\title{
The evolution of anthropomorphism in the neolithic engraved plaques of Southwestern Iberian Peninsula: a systematic approach from phylogenetics
}

\author{
Daniel García Rivero ${ }^{1, *}$ \\ ${ }^{1}$ Department of Prehistory and Archaeology, University of Seville, C/Doña María de Padilla, s/n, 41004 \\ Seville, Spain \\ *garciarivero@us.es
}

\begin{abstract}
Engraved slate plaques are a common part of the grave goods found in the Late NeolithicCopper Age I megaliths of the southwest of the Iberian Peninsula ( 3500-2700 cal BC). These objects have received a great deal of attention, since they are the first symbolic figurines to have become widespread in the Iberian Peninsula (almost 4000 plaques are estimated to be known today). Most previous studies, even from different and opposing archaeological perspectives, have highlighted the anthropomorphic nature of these plaques. The hypotheses regarding the evolution of their anthropomorphism and possible function have been diverse, yet there is a noteworthy absence of taxonomical studies in which the diversity and stylistic sequence of these symbolic objects have been systematically approached. This paper puts forward several models for the evolution of the anthropomorphism of the engraved plaques, based on cladistics and occurrence seriation. The results are then analyzed in conjunction with the currently available chronological and stratigraphic information. The paper concludes with a proposal of the most probable typology and its sequence, leading to a better understanding of the diversity and evolution of the plaques. Beyond this particular phenomenon, this paper provides insights into the study of the evolution of the symbolic representation of the human figure, through the development of an innovative methodological protocol.
\end{abstract}

\author{
Keywords \\ Neolithic \\ Copper Age \\ Iberian Peninsula \\ Taxonomy \\ Phylogenetic systematics \\ Symbology
}

\section{Introduction}

The Neolithic engraved plaques of the southwest of the Iberian Peninsula are most often made of slate. Less frequently, they are created in schist and sandstone (Fig. 1). Their distribution covers the entire southwestern sector of the Iberian Peninsula (Fig. 2), where they are recovered primarily from the funerary contexts of $\sim 200$ sites: megaliths, natural caves, shelters, artificial (rock-cut) caves, and tholoi tombs. The available radiocarbon dates range from 3468 to 2747 cal $\mathrm{BC}$, although most plaques are dated from the last quarter of the fourth millennium BC to the early second quarter of third millennium BC, that is, to the Late Neolithic-Copper Age I periods. The material culture found alongside 
the plaques usually comprises undecorated pottery and lithic tools (polished stones axes, knapped flint blades, geometric forms, and projectile points).

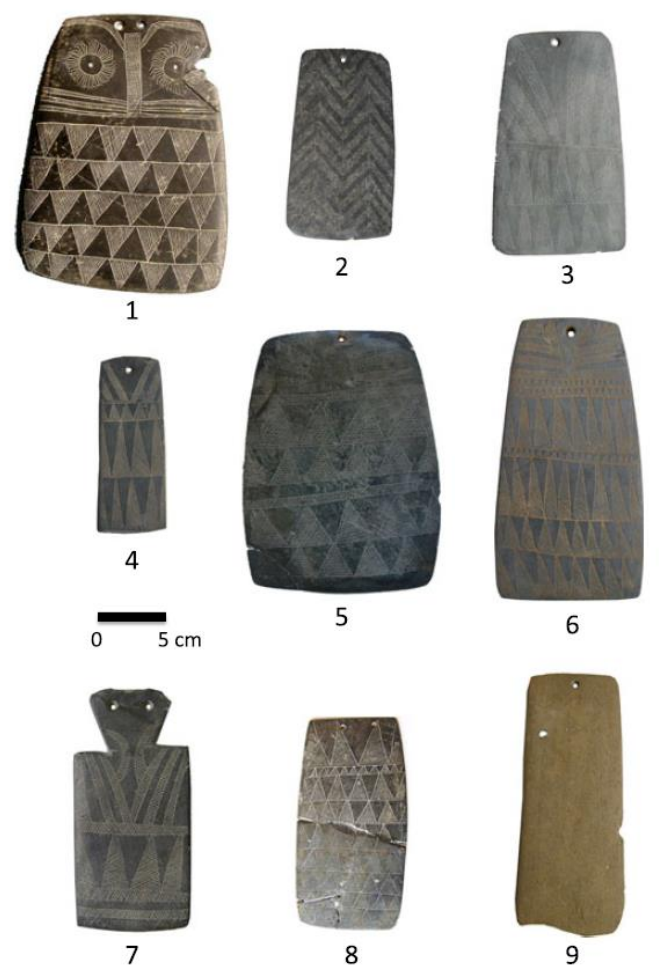

Fig. 1 Engraved plaques from the Iberian Peninsula: 1, Valencina de la Concepción, Seville, Spain (Museo Arqueológico de Sevilla [MAS]); 2, São Geraldo, Montemor-o-Novo, Évora, Portugal (Museu Nacional de Arqueologia de Portugal [MNAP]); 3, Monsaraz, Reguengos de Monsaraz, Évora (MNAP); 4, Mora, Évora (MNAP); 5, Jabugo, Aracena, Huelva, Spain (MAS); 6, Ciborro, Monte-o-Novo, Évora (MNAP); 7 , Marvão, Portalegre, Portugal (MNAP); 8, Praia das Maçãs, Lisboa (Museu Geológico de Portugal); and 9, Pavia, Mora, Évora (MNAP)

The study of these engraved plaques began in the last quarter of the nineteenth century, but in recent years, they have been the object of renewed interest and the center of ongoing discussions (cf., Lillios 2008, p. 19ff.; García Rivero and O’Brien 2014).

Most researchers have suggested a lineal stylistic evolution of the engraved plaques over time, based on the anthropomorphic figure. Abstract specimens with purely geometric motifs have been assigned to one end of that line, and very realistic anthropomorphic specimens to the other (Fig. 3). Several specialists have argued in favor of the hypothesis by which the most anthropomorphic forms would have evolved to geometric ones through a process of simplification (e.g., Frankowski 1920, p. 22; Almagro 1966, p. 38; Almagro Gorbea 1973, p. 340; Gonçalves 1978). Many other specialists have suggested that the geometric types are the oldest and that these gradually evolved into more realistic anthropomorphic figures (e.g., Correia 1917; Rodrigues 1986, p. 21, 53; Gonçalves 1989, 1992). The most important traits considered in these approaches have been the overall shape of the plaque and the way in which the most noteworthy symbols of the human figure are represented: the head, eyes, nose, and arms. It has often been assumed that these traits are a reflection of the evolutionary degree of anthropomorphic representation displayed by the plaques. Trapezoidal or rectangular shapes have been related to abstract plaques, while composite shape has been associated to a more precise representation of 
the human figure. Similarly, the head, eyes, nose, and arms are rarely present on geometric plaques but are quite realistic in more anthropomorphic plaques.

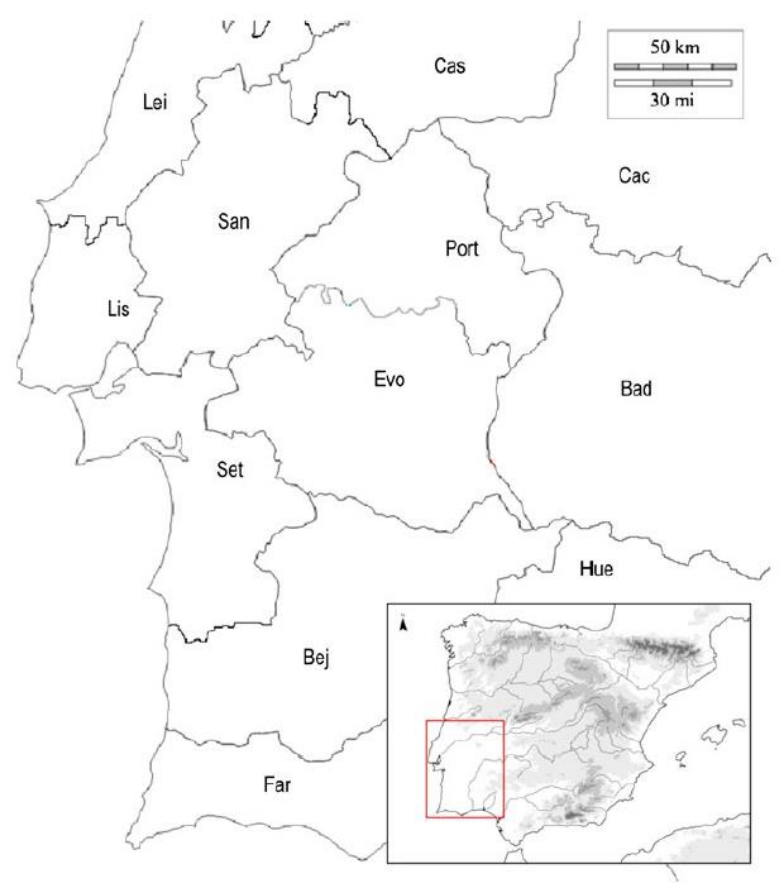

Fig. 2 Map of the Southwestern Iberian Peninsula. The names of Portuguese districts are Leiria (Lei), Lisbon (Lis), Santarem (San), Cas (Castelo Branco), Portalegre (Port), Évora (Evo), Setúbal (Set), Beja (Bej), and Faro (Far), and the Spanish provinces are Cáceres (Cac), Badajoz (Bad), and Huelva (Hue)

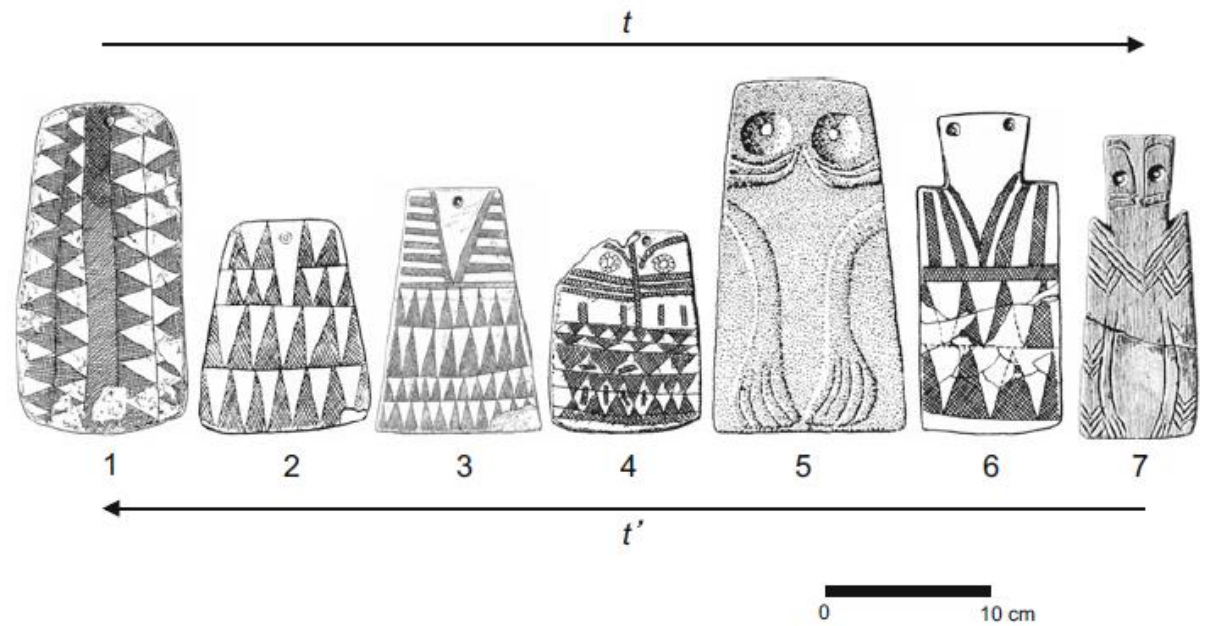

Fig. 3 Hypothetical model of the most widely accepted understanding of the evolution of the anthropomorphism of engraved plaques. This is based on an anagenetic (phyletic) model of change. The two arrows indicate the two possible polarities: on the top, from abstract to anthropomorphic plaques; on the bottom, from anthropomorphic to abstract plaques. The archaeological findspots of these plaques are as follows: 1, Comenda da Igreja, Évora; 2, Passo 1, Évora; 3, Palmela 4, Setúbal; 4, Cueva de la Mora, Huelva; 5, Espadanal, Évora; 6, Cebolinho 1, Évora; and 7, Idanha a Nova, Castelo Branco 
However, the study of engraved plaques has also envisaged a much less progressive and ordered process in which a clear temporal stylistic polarity did not take place. Among them, V. Correia (1917, p. 111) suggested a general direction from rectangular plaques to composite plaques, but he did not exclude the possibility of regressions, such as a transition from anthropomorphic figures to very abstract ones. E. Frankowski suggested a general process of gradual disappearance of the human figure (Frankowski 1920, p. 25), although he suspected that the entire assemblage of plaques need not have changed under a single, same line of change. The figures that illustrate his work (cf., Frankowski 1920, Fig. 2) showed different sequences of change. Several decades later, O. da V. Ferreira (1973) proposed the trapezoidal plaques as the earliest, but he did not exclude their possible synchrony with the anthropomorphic plaques, at least in some cases. G. \& V. Leisner suspected that geometric and much more anthropomorphic plaques could both have been simultaneous, and they insisted on the inexistence of a single evolutionary line of change for all of the types of plaques (Leisner and Leisner 1985, p. 134).

More recently, it has been argued that the (decorative) diversity of plaques has nothing to do with chronology, but rather the different types of plaques must be understood in terms of symbolic expressions related to different specific geographical areas (Bueno 1992; Hurtado 2009; Calado 2010). However, the relative chronology of the plaques has been explored by K. Lillios, who has proposed a relative sequence of the different geometric decorative motifs that appear within the lower area of the plaques (2008, p. 156ff.).

This debate surrounding the study of engraved plaques has been entirely dominated by an essentialist typological perspective and, with rare exceptions (Rodrigues 1986), there is a complete lack of taxonomical studies that have worked systematically on the diversity and evolutionary sequence of the engraved symbolic motifs of the plaques. The taxonomic task is particularly important in this case, since the detailed stratigraphic information available remains very scarce.

The main aim of this paper is to draw up the most probable (parsimonious) sequence for the development of the characters and types displayed by the engraved plaques, in order to consider the evolution of anthropomorphism. In particular, this study addresses the question of whether there is a clear lineal polarity to this anthropomorphic symbolism and, if so, which direction of change would be more likely - that is, if the realism of the representation of the human figure was accentuated or diminished in the production of plaques over time, or rather than a lineal sequence, some other more complex patterns of change were at work.

To this end, we have first carried out a deductive approach to the dataset by means of two taxonomical methods based on different theoretical models of historical change: anagenesis and phylogenesis. The anagenetic model assigns all change to a single line of ancestry, and it is useful here to verify whether the hypothesis of the lineal evolution of anthropomorphism is supported or not by the dataset. Were lineal evolution of anthropomorphism to be supported, the sequence outcome should sort the plaques according to their degree of anthropomorphism. On the contrary, the phylogenetic model acknowledges that ancestry is ramified, or tree-like. The phylogenetic model is therefore applied to explore the hypotheses regarding the possible polarities of the anthropomorphic representations, as well as to generate more complex models of how plaques may have varied and diversified over time. Two hypothetical models of the evolution of the engraved plaques have been considered: from very abstract plaques to realistic anthropomorphic ones, or the opposite direction. If one of these two models took place, the data should output better results and more consistent trees for one model than 
for the other. Because we are particularly interested in the evolution of anthropomorphism, the features of plaques that are presumably more closely related to the representation of the human figure were selected for analysis. Second, we carried out an inductive analysis and then studied all of the results in conjunction. According to the principle of consilience (Wilson 1998) - the more convergent the unrelated sources of evidences, the stronger the conclusion -we can compare the different lines of evidence in order to determine which are better substantiated. Finally, the most consistent results were checked independently (with external archaeological information) and were pooled and revised in conjunction with updated radiocarbon dates and stratigraphic information.

As we will see, this paper demonstrates the lack of a lineal model (in either of the two possible directions) for the evolution of the anthropomorphism of the Late NeolithicChalcolithic I engraved slate plaques. Rather, it enables us to suggest a complex divergent model for this anthropomorphic symbology, with diverse polarities and different tempos of continuity across several typological lineages.

\section{Materials and data}

Figures 4 and 5 show the characters and character states considered in this study. Figure 4 indicates the location of several of the main characters on a plaque. Figure 5 offers examples of specimens for each character state.

SHAP stands for the shape of the plaque. Most plaques are trapezoidal (SHAP1), others are rectangular (SHAP2) or composite (SHAP3). Structure (ST) refers to the horizontal division of a plaque into several main parts. Some plaques have either no division, or this is not sufficiently explicit (ST1). However, it is very common for plaques to be divided into two or more areas (ST2). SS codifies the vertical spatial division of the plaques. Most have no compartmented areas (SS0), but some display a frame around the perimeter of the plaque (SS1) or an empty (un-engraved) centered space (SS2). The head $(\mathrm{H})$ can be absent $(\mathrm{H} 0)$, or indicated either by an inverted triangle $(\mathrm{H} 1)$, by an inverted triangle and an appendage $(\mathrm{H} 2)$, only by an appendage (H3), or it can be clearly figurative (H4). The necklace (NK) can be either completely absent or sketched (NK0), or realistically indicated (NK1). TT stands for the straps or tattoo motifs, usually filling the upper part of the plaque. They can be absent (TT0), indicated by parallel single straps (TT1), by realistic tattoo motifs (TT2), or by any combination of straps, tattoo, or

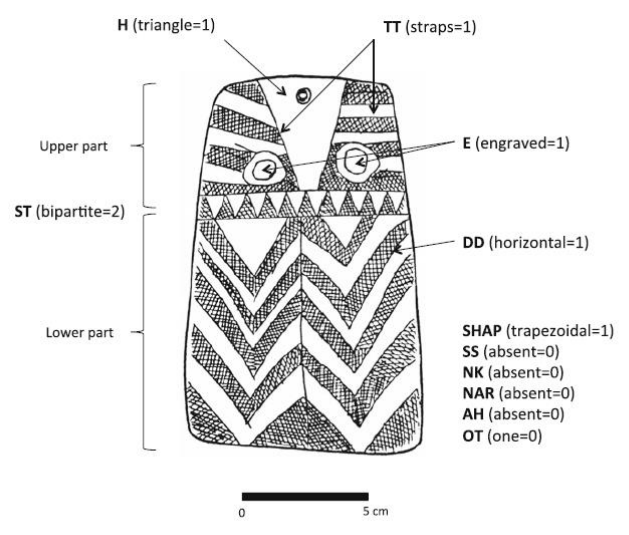

Fig. 4 Location of several of the characters considered in this study on a plaque. This plaque comes from Comenda 2, Évora (Leisner and Leisner 1985, Fig. 11, no. 71) 


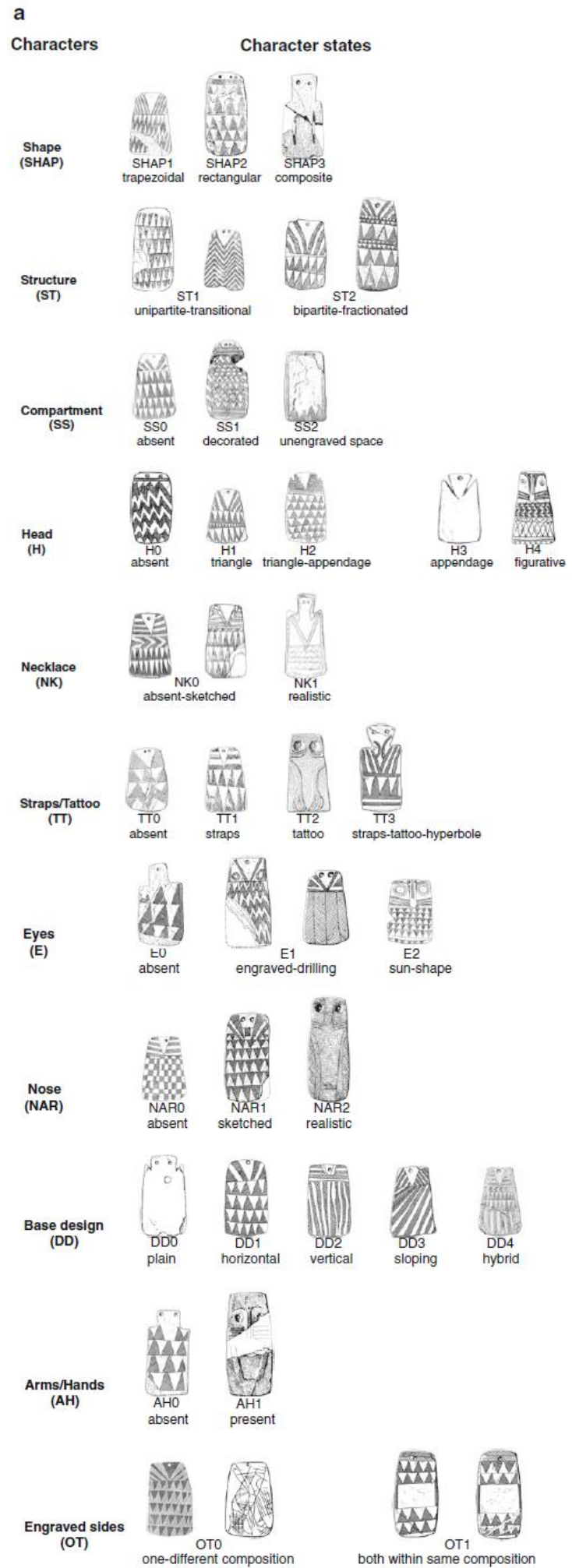

Fig. 5 Character states used in the analysis

hyperbole motifs (TT3). The eyes (E) can be absent (E0), indicated by engraved circles or drilled holes (E1), or by adding short radiating lines (sun motifs) (E2). The nose (NAR) may be absent (NAR0), sketched (NAR1), or realistic (NAR2). The main decorative motifs (DD) that cover the entire surface or the lower part of the plaque can be absent (DD0), engraved horizontally (DD1), vertically (DD2), slanting (DD3), or in a combination of directions - hybrid (DD4). The arms or hands motif (AH) can be absent (AH0) or present (AH1). Finally, OT indicates the number of engraved sides and the 
relation between them. Most plaques display a single or two unrelated engraved sides (OT0), whereas others have two engraved sides that make up a single combined composition (OT1). This paper considers the overall assemblage of currently published plaques. Although several individual or groups of plaques remain dispersed throughout the literature, the great majority of known plaques are compiled in the valuable online dataset Esprit (Lillios 2004), which includes a total of $~ 1500$ plaques. Excluding the specimens that do not allow us to correctly codify of all the aforementioned characters (fragmentary cases, lacking illustration in the database, or with misleading evidence of reengraving), we have a set of 1189 plaques. For the purpose of the present study, this dataset was deemed too large to be analyzed because of the number of classes involved (see below). It was therefore reduced to 427 specimens using a 5\% error and a 99\% confidence interval (http://www.med.unne.edu.ar/biblioteca/calculos/calculadora.htm). This sample is statistically representative of the diversity of the complete dataset. On the basis of the character states considered for this study, a paradigmatic classification was made (Dunnell 1971; O’Brien and Lyman 2000; García Rivero 2010) and only the classes that include three or more specimens were retained, following the protocol developed by previous archaeological studies (O'Brien et al. 2001; García Rivero and O'Brien 2014). As in these studies, this decision rests on the basis of considering the classes with a minimum number of specimens, which better represent the repetitive patterns rather than the more exceptional ones. The working sample was created by considering only one specimen from each class. The first specimen listed in the dataset was selected as the class representative by default. In this way, the definitive sample includes 29 paradigmatic classes (Table 1) which represent a total of 334 specimens-78.22\% of the initial 427 case dataset.

Table 1 Distribution of the frequency and percentage of specimens across the 29 classes

\begin{tabular}{llll}
\hline Class & No. of specimens & Percentage of 334 specimens & Cumulative percentage of 334 specimens \\
\hline 1 & 21 & 6.28742515 & 6.28742515 \\
2 & 6 & 1.79640719 & 8.08383234 \\
3 & 121 & 36.2275449 & 44.3113772 \\
4 & 56 & 16.7664671 & 61.0778443 \\
10 & 8 & 2.39520958 & 63.4730539 \\
11 & 5 & 1.49700599 & 64.9700599 \\
26 & 7 & 2.09580838 & 67.0658683 \\
91 & 7 & 2.09580838 & 69.1616766 \\
94 & 7 & 2.09580838 & 71.257485 \\
96 & 15 & 4.49101796 & 75.748503 \\
105 & 3 & 0.89820359 & 76.6467066 \\
130 & 8 & 2.39520958 & 79.0419162 \\
134 & 4 & 1.19760479 & 80.239521 \\
138 & 6 & 1.79640719 & 82.0359281 \\
143 & 5 & 1.49700599 & 83.5329341 \\
149 & 3 & 0.89820359 & 84.4311377 \\
174 & 3 & 0.89820359 & 85.3293413 \\
200 & 4 & 1.19760479 & 86.5269461 \\
201 & 4 & 1.19760479 & 87.7245509 \\
211 & 5 & 1.49700599 & 89.2215569 \\
219 & 6 & 1.79640719 & 91.0179641 \\
234 & 6 & 1.79640719 & 92.8143713 \\
246 & 4 & 1.19760479 & 94.011976 \\
249 & 3 & 0.89820359 & 94.9101796 \\
251 & 3 & 0.89820359 & 95.8083832 \\
273 & 3 & 0.89820359 & 96.7065868 \\
307 & 3 & 0.89820359 & 97.6047904 \\
342 & 5 & 1.49700599 & 99.1017964 \\
356 & 3 & 0.89820359 & 100 \\
& 334 & & \\
\hline
\end{tabular}


Figure 6 shows the line drawings of the 29 paradigmatic classes. Table 2 summarizes the data matrix considered in the cladistic analyses. The occurrence seriation uses this same data, but the multistate characters are encoded in a binary format in which each character state is transformed into a new character code that takes values 0 or 1 (Table 3).

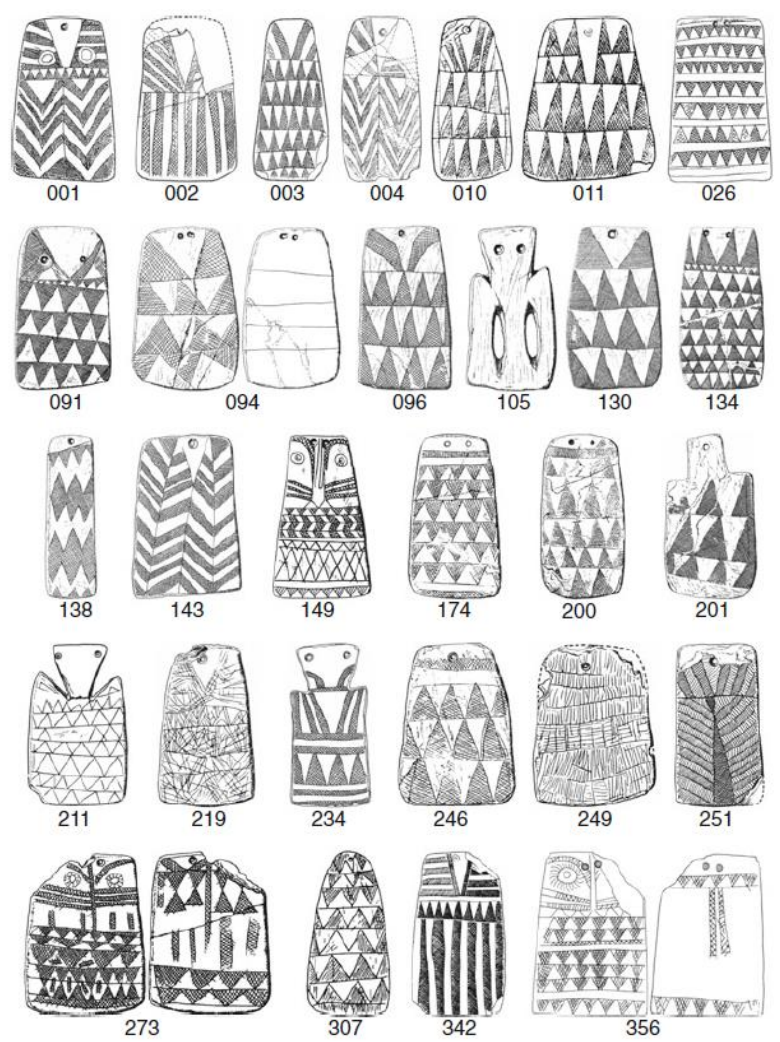

Fig. 6 Visual overview of the 29 paradigmatic classes of plaque considered in our study sample. The archaeological sites of these plaques are: 1, 2 and 3, Comenda 2, Évora; 4, Comenda 1, Évora; 10 and 11, Passo 1, Évora; 26, Tumulus de Jeromigo, Évora; 91 and 94, Dolmen das Conchadas, Lisboa; 96, Aljezur, Faro; 105, Ferreirinhos, Castelo Branco; 130 and 134, Praia das Maçãs, Lisboa; 138, Folha das Barradas, Lisboa; 143, Folha da Amendoeira, Beja; 149, Unknown location in Beja; 174, Jazigo de Alcarapinha, Portalegre; 200, Unknown location in Portugal; 201, Sobreira 2, Portalegre; 211, Cavaleiros 1, Portalegre; 219, Herdade da Ordem 1, Portalegre; 234, Marquesa, Portalegre; 246, Capela, Portalegre; 249 and 251, Comenda da Igreja, Évora; 273, Cueva de la Mora, Huelva; 307 and 342, Pedra Branca, Setúbal; and 356, Quinta da Farinheira, Lisboa

\section{Methods}

Most previous research on plaques has worked with the anagenetic (or phyletic) model of change, in which the different types of plaques are arranged in a single evolutionary line (cf., Fig. 3) and replace each other over time. The sorting technique most commonly used by this model is seriation. For the purpose of this study, we have used the occurrence seriation technique (O'Brien and Lyman 1999), which assumes historical continuity and sorts the material culture (here, the 29 paradigmatic classes) according to the considered character states (Table 3). The software OptiPath (http://www.terevaka.net/optipath/Documentation/install.htm. Accessed 27 July 2015) was used, in particular the occurrence seriation based on Manhattan distance. 
Table 2 Data matrix for the cladistic analysis

\begin{tabular}{llllllllllll}
\hline Class & SHAP & ST & SS & H & NK & T & E & NAR & DD & AH & OT \\
\hline 1 & 1 & 2 & 0 & 1 & 0 & 1 & 1 & 0 & 1 & 0 & 0 \\
2 & 1 & 2 & 0 & 1 & 0 & 1 & 0 & 0 & 2 & 0 & 0 \\
3 & 1 & 2 & 0 & 1 & 0 & 1 & 0 & 0 & 1 & 0 & 0 \\
4 & 2 & 2 & 0 & 1 & 0 & 1 & 0 & 0 & 1 & 0 & 0 \\
10 & 1 & 2 & 1 & 1 & 0 & 1 & 0 & 0 & 1 & 0 & 0 \\
11 & 1 & 1 & 0 & 1 & 0 & 0 & 0 & 0 & 1 & 0 & 0 \\
26 & 2 & 1 & 0 & 0 & 0 & 0 & 0 & 0 & 1 & 0 & 0 \\
91 & 2 & 2 & 0 & 1 & 0 & 1 & 1 & 0 & 1 & 0 & 0 \\
94 & 1 & 2 & 0 & 1 & 0 & 0 & 1 & 0 & 1 & 0 & 0 \\
96 & 2 & 2 & 0 & 1 & 0 & 0 & 0 & 0 & 1 & 0 & 0 \\
105 & 3 & 1 & 0 & 3 & 0 & 0 & 1 & 0 & 0 & 1 & 0 \\
130 & 1 & 2 & 0 & 1 & 0 & 0 & 0 & 0 & 1 & 0 & 0 \\
134 & 2 & 2 & 0 & 1 & 0 & 0 & 1 & 0 & 1 & 0 & 0 \\
138 & 2 & 2 & 0 & 0 & 0 & 0 & 0 & 0 & 1 & 0 & \\
143 & 2 & 1 & 0 & 1 & 0 & 0 & 0 & 0 & 1 & 0 & 0 \\
149 & 1 & 2 & 0 & 4 & 0 & 2 & 1 & 2 & 1 & 0 & 0 \\
174 & 1 & 2 & 0 & 0 & 0 & 0 & 1 & 0 & 1 & 0 & 0 \\
200 & 2 & 2 & 0 & 0 & 0 & 0 & 1 & 0 & 1 & 0 & 0 \\
201 & 3 & 2 & 0 & 3 & 0 & 0 & 0 & 0 & 1 & 0 & 0 \\
211 & 3 & 2 & 0 & 3 & 0 & 0 & 1 & 0 & 1 & 0 & 0 \\
219 & 1 & 2 & 0 & 1 & 0 & 1 & 0 & 0 & 4 & 0 & 0 \\
234 & 3 & 2 & 0 & 3 & 0 & 3 & 1 & 0 & 1 & 0 & 0 \\
246 & 1 & 2 & 0 & 0 & 0 & 0 & 0 & 0 & 1 & 0 & 0 \\
249 & 2 & 1 & 0 & 0 & 0 & 0 & 0 & 0 & 4 & 0 & 0 \\
251 & 2 & 2 & 1 & 1 & 0 & 1 & 0 & 0 & 4 & 0 & 0 \\
273 & 2 & 2 & 0 & 4 & 0 & 2 & 2 & 2 & 1 & 0 & 1 \\
307 & 1 & 1 & 0 & 0 & 0 & 0 & 0 & 0 & 1 & 0 & 0 \\
342 & 2 & 2 & 0 & 1 & 0 & 1 & 0 & 0 & 2 & 0 & 0 \\
356 & 1 & 2 & 0 & 4 & 0 & 2 & 2 & 2 & 1 & 0 & 1 \\
\hline & & & & & & & & & & &
\end{tabular}

However, the divergent evolutionary model is most commonly applied in biology. Different species can derive from asingle ancestor, under the model known as phylogenetic. This divergent-cladogenetic or branching evolution-model reflects the nature of evolutionary change, both in living organisms and in material culture (O'Brien and Lyman 2000, 2003; García Rivero 2013). Rather than assigning all change to a single line of ancestry, as is the case in phyletic seriation, the cladogenetic model recognizes that ancestry is ramified, or tree-like. Thus, evolutionary lineages or branches may become extinct or exist simultaneously, and it is even possible for several branches to remain without any changes over long periods of time, while others evolve quickly.

Phylogenetic reconstruction is currently the main method used to construct testable hypotheses of ancestor-descendant relationships (e.g., Lycett et al. 2007; Cap et al. 2008; O'Leary and Gatesy 2008; Smith and Grine 2008). The logical basis for extending the use of phylogenetics into archaeology is the same as it is in biology: Artifacts are complex systems, comprising any number of parts that act in concert to produce a functional unit. The kinds of changes that may occur over generations of, say, stone plaque manufacture are highly constrained in the sense that new structures and functions usually stem from the modification of existing structures and functions as opposed to emerging de novo (O'Brien et al. 2012). Thus, "the history of these changes is recorded in the similarities and differences in the complex characteristics of related [objects] - in the extent to which the characteristics of their common ancestors have been modified by subsequent additions, losses, and transformations" (Brown and Lomolino 1998, p. 328). 
Table 3 Data matrix for the occurrence seriation analysis

\begin{tabular}{llllllllllll}
\hline Class & SHAP1 & SHAP2 & SHAP3 & ST1 & ST2 & SS & H0 & H1 & H2 & H3 & H4 \\
\hline 1 & 1 & 0 & 0 & 0 & 1 & 0 & 0 & 1 & 0 & 0 & 0 \\
2 & 1 & 0 & 0 & 0 & 1 & 0 & 0 & 1 & 0 & 0 & 0 \\
3 & 1 & 0 & 0 & 0 & 1 & 0 & 0 & 1 & 0 & 0 & 0 \\
4 & 0 & 1 & 0 & 0 & 1 & 0 & 0 & 1 & 0 & 0 & 0 \\
10 & 1 & 0 & 0 & 0 & 1 & 1 & 0 & 1 & 0 & 0 & 0 \\
11 & 1 & 0 & 0 & 1 & 0 & 0 & 0 & 1 & 0 & 0 & 0 \\
26 & 0 & 1 & 0 & 1 & 0 & 0 & 1 & 0 & 0 & 0 & 0 \\
91 & 0 & 1 & 0 & 0 & 1 & 0 & 0 & 1 & 0 & 0 & 0 \\
94 & 1 & 0 & 0 & 0 & 1 & 0 & 0 & 1 & 0 & 0 & 0 \\
96 & 0 & 1 & 0 & 0 & 1 & 0 & 0 & 1 & 0 & 0 & 0 \\
105 & 0 & 0 & 1 & 1 & 0 & 0 & 0 & 0 & 0 & 1 & 0 \\
130 & 1 & 0 & 0 & 0 & 1 & 0 & 0 & 1 & 0 & 0 & 0 \\
134 & 0 & 1 & 0 & 0 & 1 & 0 & 0 & 1 & 0 & 0 & 0 \\
138 & 0 & 1 & 0 & 0 & 1 & 0 & 1 & 0 & 0 & 0 & 0 \\
143 & 0 & 1 & 0 & 1 & 0 & 0 & 0 & 1 & 0 & 0 & 0 \\
149 & 1 & 0 & 0 & 0 & 1 & 0 & 0 & 0 & 0 & 0 & 1 \\
174 & 1 & 0 & 0 & 0 & 1 & 0 & 1 & 0 & 0 & 0 & 0 \\
200 & 0 & 1 & 0 & 0 & 1 & 0 & 1 & 0 & 0 & 0 & 0 \\
201 & 0 & 0 & 1 & 0 & 1 & 0 & 0 & 0 & 0 & 1 & 0 \\
211 & 0 & 0 & 1 & 0 & 1 & 0 & 0 & 0 & 0 & 1 & 0 \\
219 & 1 & 0 & 0 & 0 & 1 & 0 & 0 & 1 & 0 & 0 & 0 \\
234 & 0 & 0 & 1 & 0 & 1 & 0 & 0 & 0 & 0 & 1 & 0 \\
246 & 1 & 0 & 0 & 0 & 1 & 0 & 1 & 0 & 0 & 0 & 0 \\
249 & 0 & 1 & 0 & 1 & 0 & 0 & 1 & 0 & 0 & 0 & 0 \\
251 & 0 & 1 & 0 & 0 & 1 & 1 & 0 & 1 & 0 & 0 & 0 \\
273 & 0 & 1 & 0 & 0 & 1 & 0 & 0 & 0 & 0 & 0 & 1 \\
307 & 1 & 0 & 0 & 1 & 0 & 0 & 1 & 0 & 0 & 0 & 0 \\
342 & 0 & 1 & 0 & 0 & 1 & 0 & 0 & 1 & 0 & 0 & 0 \\
356 & 1 & 0 & 0 & 0 & 1 & 0 & 0 & 0 & 0 & 0 & 1 \\
\hline
\end{tabular}

In recent years, phylogenetics has begun to be widely implemented in archeology (e.g., O'Brien et al. 2001, 2002, 2008, 2012; Darwent and O'Brien 2006; Harmon et al. 2006; Buchanan and Collard 2007, 2008; Lycett 2007; Cochrane 2008; Riede 2008; Cardillo 2010; Marwick 2012; GarcíaRivero and O’Brien 2014; Jennings andWaters 2014) and otherfields of material culture studies (e.g., Tehrani and Collard 2002, 2009a, 2009b; Jordan and Shennan 2003, 2009; Shennan and Collard 2005; Jordan and Mace 2006; Shennan 2009; Jordan and O'Neill 2010; Tehrani et al. 2010; Prentiss et al. 2015). Phylogenetic relationships are defined in terms of the relative recency of common ancestry: Two taxa are deemed to be more closely related to one another than to a third taxon as long as the former share a common ancestor that is not also shared by the latter. The evidence for exclusive common ancestry is the sharing of evolutionary novelty, as is illustrated in Fig. 7. In (a), a new character appears in the line that will later split to produce taxa $\mathrm{C}$ and $\mathrm{D}$. After the split, both sister taxa exhibit that character, referred to as a shared derived character, or synapomorphy. In (b), a new character makes an initial appearance in the line that will produce B, C, and D. By the time C and D split, the character can be defined as a shared ancestral trait, or symplesiomorphy. It would be impossible to figure out the phylogenetic relationship between $\mathrm{B}, \mathrm{C}$, and D by using only that character, because it is shared by all three taxa. In (c), the same new character appears in two distantly related lines that do not share an immediate common ancestor.

Such a character is referred to as a homoplasy. 

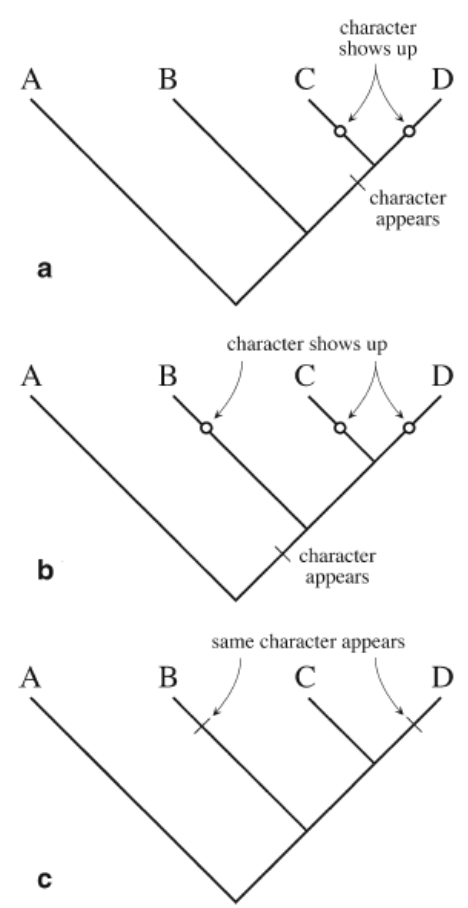

Fig. 7 Three hypothetical phylogenetic trees for the possible appearance of characters (traits)

Various methods have been used for phylogenetic inference, each based on different models and each with its own strengths and weaknesses (Pol and Siddall 2001; Archibald et al. 2003; Sober 2004; Goloboff and Pol 2005; Holden et al. 2005). The one used here, maximum parsimony, is based on a model that seeks to identify the smallest number of evolutionary steps required to arrange the taxonomic units under study. In its most simple form, the method consists of four stages. First, a data matrix is generated that shows the states of the characters exhibited by each taxon. Second, the direction (polarity) of evolutionary change among the states of each character is established. One method for this is outgroup analysis (Maddison et al. 1984; García Rivero 2013, p. 137), which entails examining a close relative of the study group, a so-called outgroup. When a character occurs in two states in the study group, but only one of the states is found in the outgroup, the principle of parsimony is invoked (see below) and the state found only in the study group is deemed to be evolutionarily novel with respect to the outgroup state, thus determining the polarity of the evolutionary change. Applied to archaeological case studies, occurrence seriation can be successfully applied to select an appropriate outgroup (O'Brien et al. 2002). Third, a branching diagram is constructed that represents the relationships between the characters under study. This is done by joining the two most derived taxa-C and D in Fig. 7-by two connecting lines and then successively connecting each of the other taxa according to the extent to which they are derived. In Fig. 7, for example, taxon B is more derived than taxon A. Each group of taxa defined by a cluster of connecting lines corresponds to a clade, and groups of related clades are referred to as trees. More precisely, a clade consists of two or more taxa and their immediate ancestor. In Fig. 7, there are three clades: $\mathrm{C}+\mathrm{D}+$ their closest common ancestor, $\mathrm{B}+\mathrm{C}+\mathrm{D}+$ their closest common ancestor, and $\mathrm{A}+\mathrm{B}+\mathrm{C}+\mathrm{D}+$ their closest common ancestor. Ideally, the distribution of the character states among the taxa should be such that all of the characters imply congruent relationships. More often, however, a number of characters may suggest relationships that are incompatible due to homoplasy. Figure 7 
shows an instance of homoplasy, the appearance of the same character in two lines but not in a third related line. This problem is overcome through the fourth and final stage of the maximum parsimony method. A consensus tree is generated that is consistent with the largest number of characters and, therefore, requires the smallest number of homoplasies to account for the distribution of the character states among the taxa. We refer to such a tree as the "most parsimonious" solution. Parsimony trees are evaluated on the basis of the minimum number of character-state changes required, and they constitute hypothetical statements about the taxa relationships, based on the parameters and data considered.

Numerous techniques are available for measuring the degree of agreement between a dataset and a given tree. Consistency index (CI), retention index (RI), and rescaled consistency index (RC) are the most commonly used. The CI measures the relative amount of homoplasy in a dataset but is dependent on the number of taxa. Thus, the expected CI for a given tree must be assessed in relation to the number of taxa used in the analysis (Sanderson and Donoghue 1989). The RI measures the number of similarities in a dataset that are retained as homologies in any given tree. It is insensitive to both the presence of derived character states that appear only in a single taxon and the number of characters or taxa considered. Thus, it can be compared between studies. The rescaled consistency index (RC) is the product of the consistency index and the retention index. These indices may range from 0 to 1 , with 0 indicating the complete lack of fit between a tree and the dataset from which it was generated, and 1 indicating a perfect fit.

The characters considered here are all related to the more or less explicit representation of an anthropomorphic figure. They can take different values (character states) depending on the degree of the anthropomorphism of the plaques. Character states can be ordered, which implies that there are defined and limited pathways that a character transformation may take (Slowinski 1993). For instance, it may be the case that evolutionary "laws" dictate that an organism can lose or gain only one toe at a time. From initially four toes, an organism could develop a fifth toe or lose one and have but three, but it could never skip either from having five toes to having three, or from having two to four. The character "number of toes", then, would be said to have ordered character states. Moreover, an ordered transformation series is in itself a hypothesis about a particular pathway because we seldom know what is possible in Nature. The two working hypotheses here regarding the polarity of change are as follows: from very abstract plaques to realistic anthropomorphic ones (hereafter abstract $\rightarrow$ anthropomorphic), or inversely (anthropomorphic $\rightarrow$ abstract). But not all of the characters of the plaques are relevant to this matter. For example, the general trapezoidal or rectangular shape of a plaque is not related to the determination of polarity, while the way of representing the head, which may range from the absence of this motif (H0) to its realistic representation being clearly figurative (H4), or vice versa, is strongly related (cf., Fig. 5). The states of the characters that are related to the polarity of anthropomorphism $(\mathrm{H}, \mathrm{TT}, \mathrm{E}, \mathrm{NAR}, \mathrm{AH}$, and OT) have been ordered. The NK character has not been ordered since the data matrix (Table 2) has no paradigmatic class with value 1 . This is supported by the matrix of costs created for each character (Fig. 8). These matrices establish the cost for every possible transition between the character states that are implemented by the algorithm that searches for cladograms. For example, considering the polarity "abstract $\rightarrow$ anthropomorphic" for character $\mathrm{H}$, any transition in accordance with this direction, even the nonconsecutive transitions (for example, $0 \rightarrow 2$ ), is assigned the minimum cost of 1 , while any unexpected transition (for example, $4 \rightarrow 3$ or $2 \rightarrow 0$ ) is given the maximum (penalized) cost of 2 . For this reason, all of the matrices are symmetrical, and they are exactly opposite when considering the two possible polarities. 
POLARITY ABSTRACT $\rightarrow$ ANTHROPOMORPH
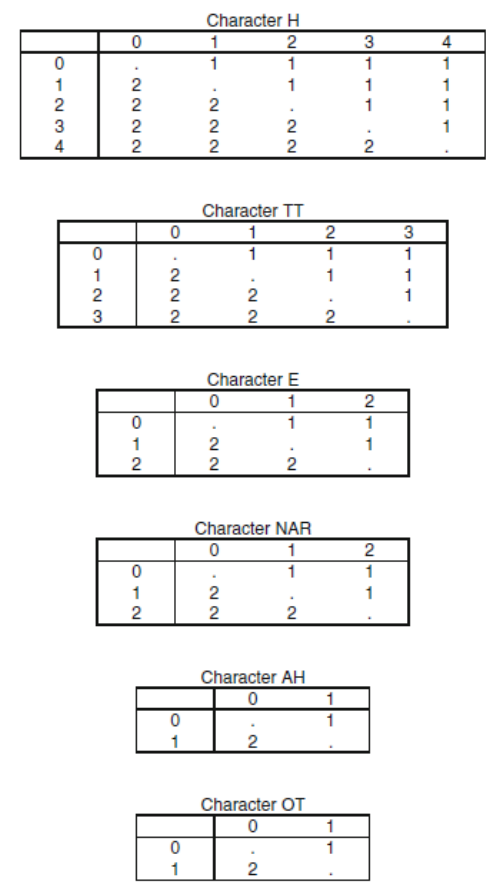

POLARITY ANTHROPOMORPH $\rightarrow$ ABSTRACT
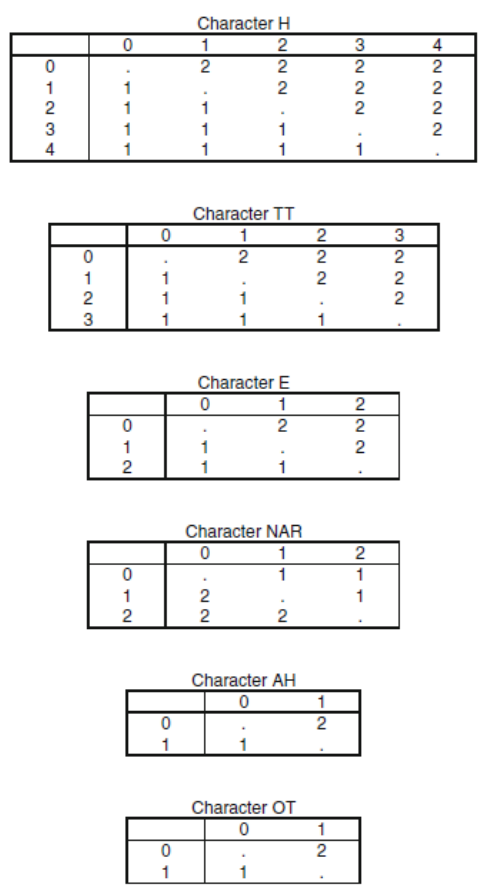

Fig. 8 Costs of transitions between states of characters H, TT, E, NAR, AH, and OT for the two polarities. Transitions must be always read from the left column to the upper line. For example, in in case of character $\mathrm{H}$ in the polarity abstract $\rightarrow$ anthropomorph, the transition from the state 0 to the state 1 has the minimum cost "1", while the unexpected transition from the state 1 to the state 0 has the (penalized) maximum cost of "2"

The last important point here, mentioned above, is the choice of outgroup, that is, the choice of the paradigmatic class that will be located at the base of the tree and from which all other classes will develop. For every working hypothesis, the most appropriate outgroup must be determined. In relation to the abstract $\rightarrow$ anthropomorphic polarity, the outgroup must be as abstract as possible. Class no. 26 and no. 3 were considered the best suited - the former because it displays the greatest number of ancestral states (values 0 in Table 2) and the latter because it corresponds to the abstract plaques that many specialists have named "classic" and have suggested as the oldest type (e.g., Gonçalves 2003b, 2004; Lillios 2008). In relation to the "anthropomorphic $\rightarrow$ abstract" polarity, the outgroup must be as anthropomorphic as possible, that is, the classes with the higher values (farthest from 0). Following this criterion, class no. 105 and no. 356 were selected as the more appropriate for this hypothesis (Table 2).

Four different exercises were carried out on the dataset (Table 2). Each exercise corresponds to a single combination of polarity and outgroup. The exercises searched for the best supported tree using the "parsimony heuristic search" in Paup 4.0 (http://paup.csit.fsu.edu/. Accessed 27 July 2015) (Table 4). All searches were carried out using the stepwise-addition strategy for the addition of classes, with a simple addition sequence and retaining only one tree at each step; the tree bisection and reconnection method, with the branch-swapping algorithm for the tree rearrangements; and a maximum set of 100 for the initial trees. For each exercise, a majority rule consensus tree was created in order to reconcile the different possible outcomes. 
Table 4 Parameters used for the cladistic analyses

\begin{tabular}{llll}
\hline Exercise & Polarity & Outgroup & Method \\
\hline 1 & Abstract $\rightarrow$ anthropomorphism & 3 & HS/MR \\
2 & Abstract $\rightarrow$ anthropomorphism & 26 & HS/MR \\
3 & Anthropomorphism $\rightarrow$ abstract & 105 & HS/MR \\
4 & Anthropomorphism $\rightarrow$ abstract & 356 & HS/MR \\
\hline
\end{tabular}

$H S$ heuristic search, $M J$ majority-rule consensus tree

\section{Results}

Figure 9 illustrates the outcome of the occurrence seriation. Because the seriation does not assume a particular polarity, the outcome can be read in both directions. Most anthropomorphic plaques appear at both ends of the seriation (see class nos. 273, 356, 149, and 1 at one end, and class nos. 105, 234, 211, and 201 at the other). This observation is contrary to the expectation and therefore refutes, on the basis of current data, the hypothesis of a lineal evolution of the representation of the human figure on the engraved plaques.

\begin{tabular}{|c|c|c|c|}
\hline \multirow{2}{*}{ 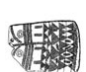 } & Classes & Order & Distances \\
\hline & 273 & 1 & 0,090 \\
\hline \multirow{4}{*}{ 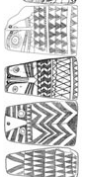 } & 356 & 2 & 0,113 \\
\hline & 149 & 3 & 0,147 \\
\hline & 1 & 4 & 0,215 \\
\hline & 3 & 5 & 0,238 \\
\hline 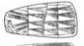 & 10 & 6 & 0,250 \\
\hline \multirow{3}{*}{ 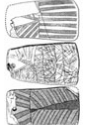 } & 2 & 7 & 0,284 \\
\hline & 219 & 8 & 0,306 \\
\hline & 251 & 9 & 0,340 \\
\hline 歫流 & 342 & 10 & 0,375 \\
\hline \multirow{2}{*}{ SEI } & 4 & 11 & 0,397 \\
\hline & 91 & 12 & 0,420 \\
\hline 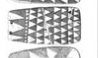 & 134 & 13 & 0,443 \\
\hline \multirow{4}{*}{$\frac{2}{333}$} & 94 & 14 & 0,465 \\
\hline & 130 & 15 & 0,488 \\
\hline & 96 & 16 & 0,511 \\
\hline & 143 & 17 & 0,534 \\
\hline \multirow{2}{*}{ 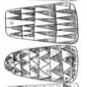 } & 11 & 18 & 0,556 \\
\hline & 307 & 19 & 0,579 \\
\hline 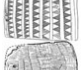 & 26 & 20 & 0,602 \\
\hline \multirow{2}{*}{ हE3 } & 249 & 21 & 0,625 \\
\hline & 138 & 22 & 0,670 \\
\hline \multirow{2}{*}{$\begin{array}{l}1-83 \\
\text { frese }\end{array}$} & 200 & 23 & 0,693 \\
\hline & 174 & 24 & 0,715 \\
\hline 130 & 246 & 25 & 0,738 \\
\hline \multirow[t]{2}{*}{ 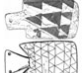 } & 201 & 26 & 0,784 \\
\hline & 211 & 27 & 0,806 \\
\hline 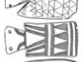 & 234 & 28 & 0,829 \\
\hline & 105 & 29 & 0,909 \\
\hline
\end{tabular}

Fig. 9 Occurrence seriation result. The order can be read in both directions, either from top to bottom or in the opposite direction 
Table 5 includes the following scores for each parsimony heuristic search: branch length of trees, consistency index, retention index, and rescaled consistency index (cf., Forey et al. 2002, p. 72ff.;Wiley et al. 1991, p. 71ff.). The parsimony scores are very similar between all of the exercises in such a way that there is not enough evidence in favor or against either of the two polarities of change or any of the possible outgroups. The retention index values indicate some coherence and phylogenetic structure within the dataset, but the consistency index values display a very low agreement between the dataset and the trees. This indicates that neither of the two hypothetical models (from very abstract plaques to realistic anthropomorphic ones, or inversely) is well supported by the data and that this analysis provides further evidence against a progressive lineal evolution of the anthropomorphism of plaques.

Figures 10, 11, 12, and 13 show the majority consensus trees. The exhaustive analysis of the structure and topology of these trees enables a number of relevant observations. As can be seen (Figs. 10, 11, 12, and 13), the more systematic groups (arranged according to how repetitive they are) are class nos. 251, 342, and 219 (clade $h$ ); class nos. 105, 211, 234, and 105 (clade $c$ ); class nos. 273, 356, 149, and partly 94 (clade f); class nos. 26, 249, 143, and partly 11, 96, 138, and 130 (clade $u$ ); and class nos. 246, 307 , and/or 174, and 200 (clade $l$ ).

Table 5 Parsimony heuristic search scores

\begin{tabular}{llllll}
\hline Exercise & $\begin{array}{l}\text { Length of } \\
\text { cladograms }\end{array}$ & $\begin{array}{l}\text { Consistence } \\
\text { index }\end{array}$ & $\begin{array}{l}\text { Retention } \\
\text { index }\end{array}$ & $\begin{array}{l}\text { Rescaled consistence } \\
\text { index }\end{array}$ & $\begin{array}{l}\text { Majority rule } \\
\text { tree }\end{array}$ \\
\hline 1 & 35 & 0.200 & 0.627 & 0.125 & Fig. 10 \\
2 & 35 & 0.200 & 0.627 & 0.125 & Fig. 11 \\
3 & 38 & 0.184 & 0.693 & 0.128 & Fig. 12 \\
4 & 38 & 0.184 & 0.693 & 0.128 & Fig. 13 \\
\hline
\end{tabular}

Clade $h$ is characterized by the complex decoration on the lower part of the plaques (DD4) and corresponds to the type named hybrid (Gonçalves 2003b, 2006) or variant (Lillios 2008) by other authors (Fig. 14). Clade $c$ is characterized by a composite shape (SHAP3) with an appendage for the head (H3). This clade would include the types described as hoe, strappy, and maybe also biomorph simple by Lillios (2008, p. 59ff.). This kind of plaque has more generally been named composite (Almagro Gorbea 1973, p. 181ff.; Gonçalves 2003b, p. 251). Clade $f$ is characterized by a figurative head (H4) and tattoo (TT2), and partly by a single composition on both sides of the plaques (OT1). Several authors have previously described these as plaques with facial symbols (Leisner and Leisner 1985), geometric plaques with tattoos (Gonçalves 2004, p. 172ff.), or biomorph whiskered plaques (Lillios 2008, p. 70). Clade $u$ is characterized by a unipartite or transitional structure (ST1). In the literature, these are known as continuous decoration plaques (Rodrigues 1986), plaques with no distinction areas (Gonçalves 1992), or unipartite plaques (Lillios 2008, p. 59). Clade $l$ is characterized by a headless (H0) and bipartite structure (ST2). This kind of plaque has never been defined as a type in previous studies and has usually been grouped within other more general types such as the unipartite (Lillios 2008). It is of great interest that our approach has systematically grouped these plaques as a different type. The rest of the classes are not systematically sorted into well-defined clades. They correspond mainly to plaques that authors have previously named classic plaques (for example, class nos. 2, 3, and 10 -indicated by the letter $s$ in the trees) and loucas (Gonçalves 2003a) or peculiar geometric plaques (García 


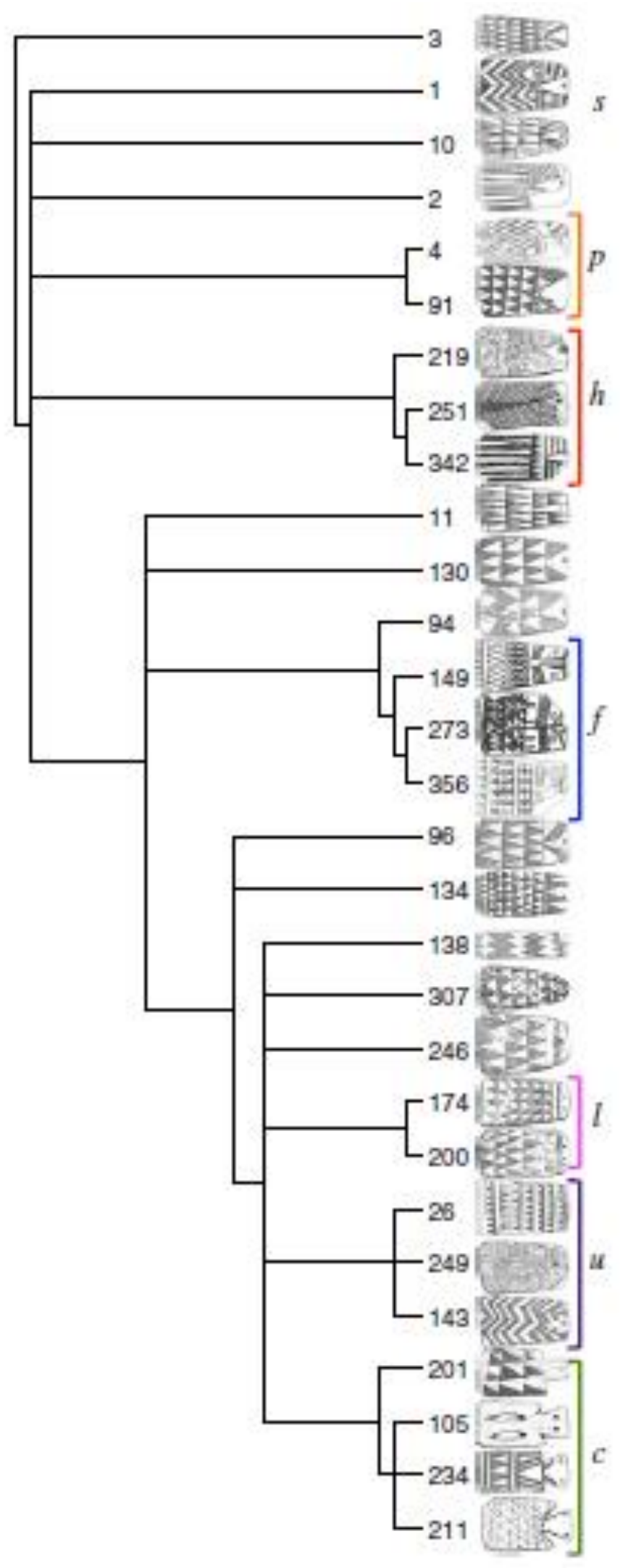

Fig. 10 Fifty-percent majority-rule consensus tree from exercise 1 . The tree was obtained with the polarity anthropomorph $\rightarrow$ abstract and the class no. 3 as the outgroup. Letters indicating clades (types) (here, $p, h, f$, $l, u$, and $c$ ) are bracketed. Otherwise, they indicate associations of classes that are recurrent (here, $s$ ) 


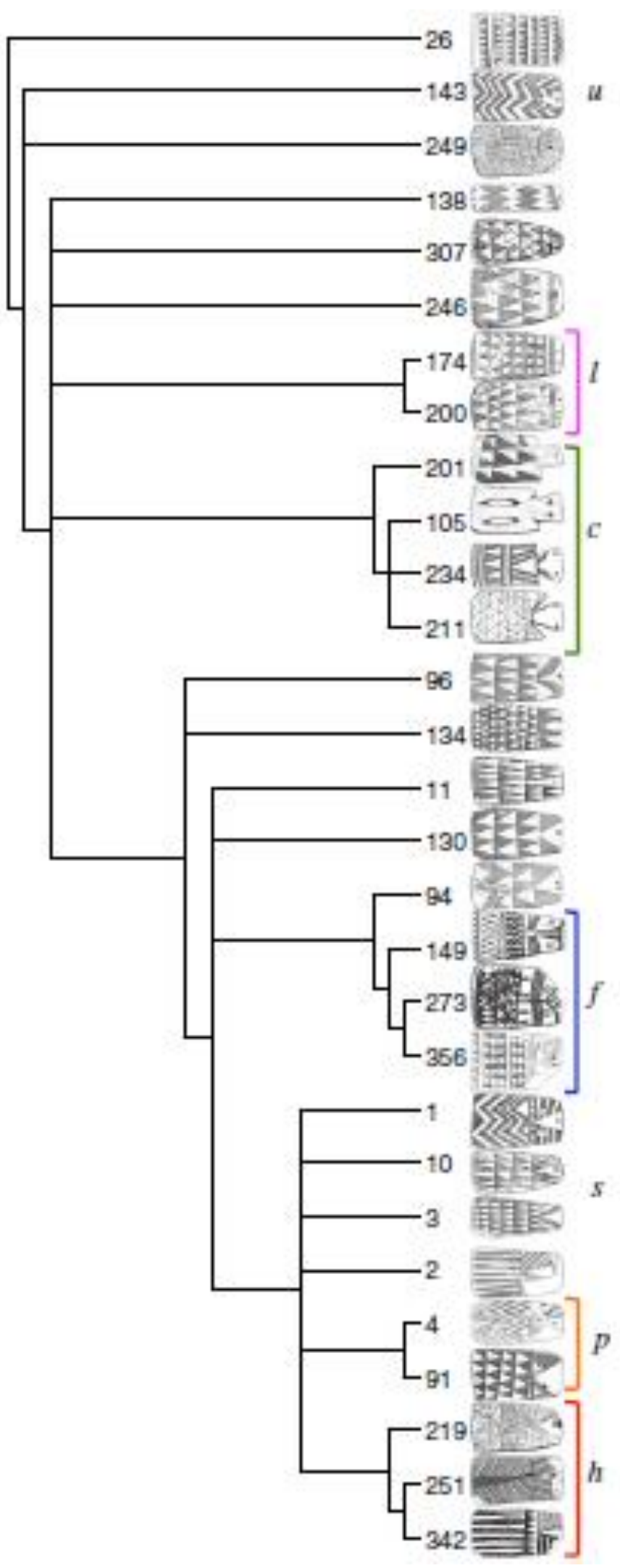

Fig. 11 Fifty-percent majority-rule consensus tree from exercise 2. The tree was obtained with the polarity anthropomorph $\rightarrow$ abstract and the class no. 26 as the outgroup. Letters indicating clades (types) (here, $l, c, f, p$, and $h$ ) are bracketed. Otherwise, they indicate associations of classes that are recurrent (here, $u$, and $s$ ) 


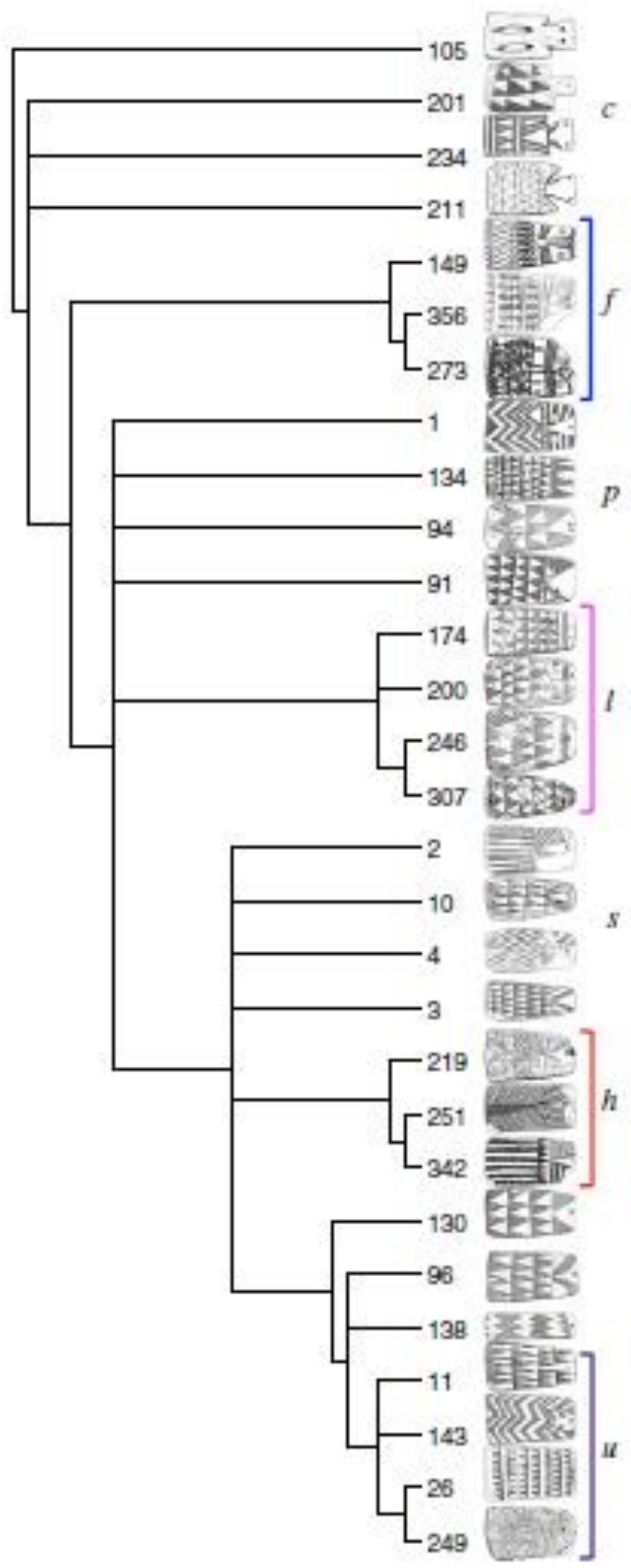

Fig. 12 Fifty-percent majority-rule consensus tree from exercise 3. The tree was obtained with the polarity abstract $\rightarrow$ anthropomorph and the class no. 105 as the outgroup. Letters indicating clades (types) (here, $f, l$, $h$, and $u$ ) are bracketed. Otherwise, they indicate associations of classes that are recurrent (here, $c, p$, and $s$ ) 


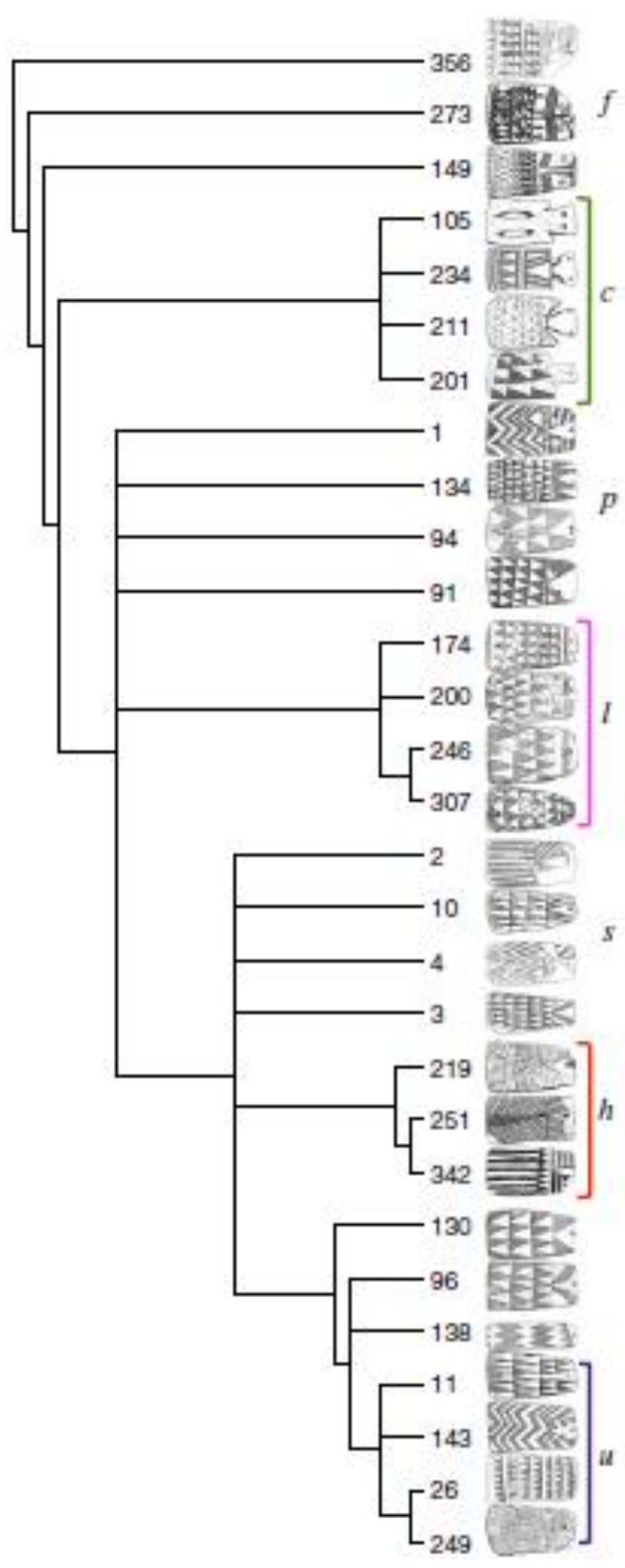

Fig. 13 Fifty-percent majority-rule consensus tree from exercise 4. The tree was obtained with the polarity abstract $\rightarrow$ anthropomorph and the class no. 356 as the outgroup. Letters indicating clades (types) (here, $c$, $l, h$, and $u$ ) are bracketed. Otherwise, they indicate associations of classes that are recurrent (here, $f, p$, and s) 
Rivero 2010, Evolución cultural y filogenias en Arqueología. El caso de los denominados ídolos placa prehistóricos del Suroeste de la Península Ibérica. Unpublished doctoral thesis, University of Seville, p. 452) (for example, class nos. 4, 91, and 134-indicated by the letter $p$ in the trees).

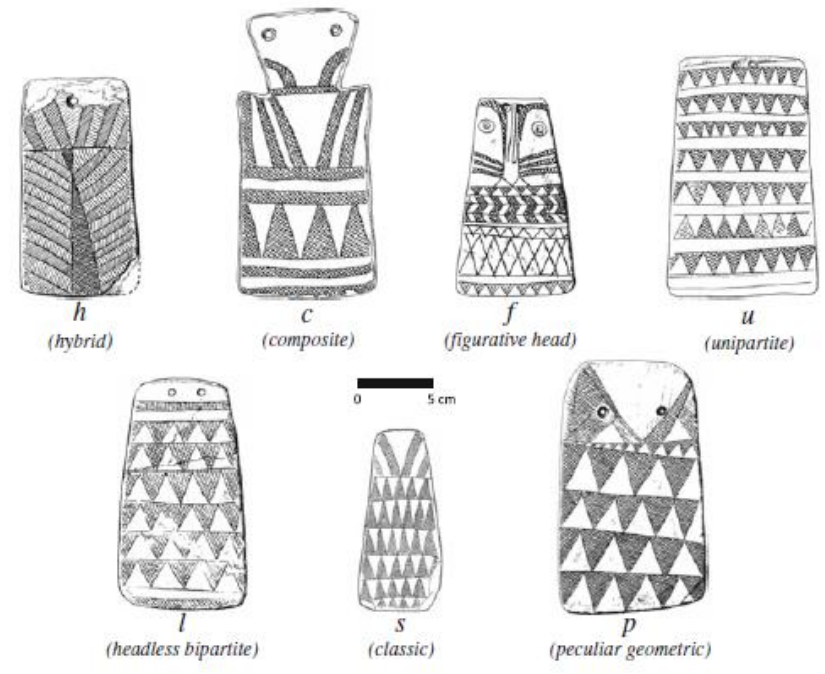

Fig. 14 Hypothetical typology of engraved plaques obtained from sorting analysis. Both cladistics and seriation analysis support types $h, c, f, u$, and $l$, whereas $s$ and $p$ are only supported by seriation (see below)

The analysis of the relationship between clades is interesting in order to deduce ancestry patterns. First, both anthropomorphic $\rightarrow$ abstract polarity trees have almost the same structure (Figs. 12 and 13).With the exception of the interchanged positions of the clades $c$ (composite plaques) and $f$ (figurative head plaques) at the base, the rest of the trees are identical. This indicates a kind of convergence that may reflect the consistency of the phylogenetic structure of this polarity model. Tree with class no. 356 as its outgroup (Fig. 13) may help solve the basal area a little better. The stable ancestry pattern for this polarity is as follows: From the most anthropomorphic plaques (types $f$ and $c$ ), the headless bipartite plaques $(l)$ would evolve, along with several peculiar geometric plaques $(p)$ and a further more hierarchical group, which assembles the classic plaques $(s)$ through a polytomy, together with the hybrid plaques $(h)$ and a clade that includes several peculiar geometric plaques at its base and the unipartite plaques $(u)$.

Second, the abstract $\rightarrow$ anthropomorphic polarity trees (Figs. 10 and 11) display more different structures. They both have abstract plaques as ancestors, but the order in which the clades appear along the trees is almost reversed. The clades that appear at the base of Fig. 10 are located close to the tips of Fig. 11, whereas those located close to the tips of Fig. 10 appear at the base of Fig. 11. The tree with class no. 3 as its outgroup (Fig. 10) has a basal polytomy that groups together the plaques $s$, a clade of plaques $p$, type $h$, and a more hierarchical clade that includes several plaques $p$, type $f$, and another derived clade containing several plaques $p$ and a polytomy with types $l, u$, and $c$. In contrast, the tree with class no. 26 as its outgroup (Fig. 11) has type $u$ on the base followed by a polytomy that assembles types $l, c$, and another hierarchical clade with several plaques $p$ at its base, followed by a polytomy with type $\mathrm{f}$ and a derived clade that contains plaques $s$ and $p$, and type $h$. 
As a final remark before closing this section, we must recall the result of the occurrence seriation. As can now be highlighted in colored brackets (Fig. 15), all of the clades suggested by the phylogenetic trees remain stable in the seriation. This provides further support for the proposed typology. In the seriation, the order of plaques is (beginning by default from the top) as follows: type $f$, plaques $s$, type $h$, plaques $p$, type $u$, type $l$, and type $c$.

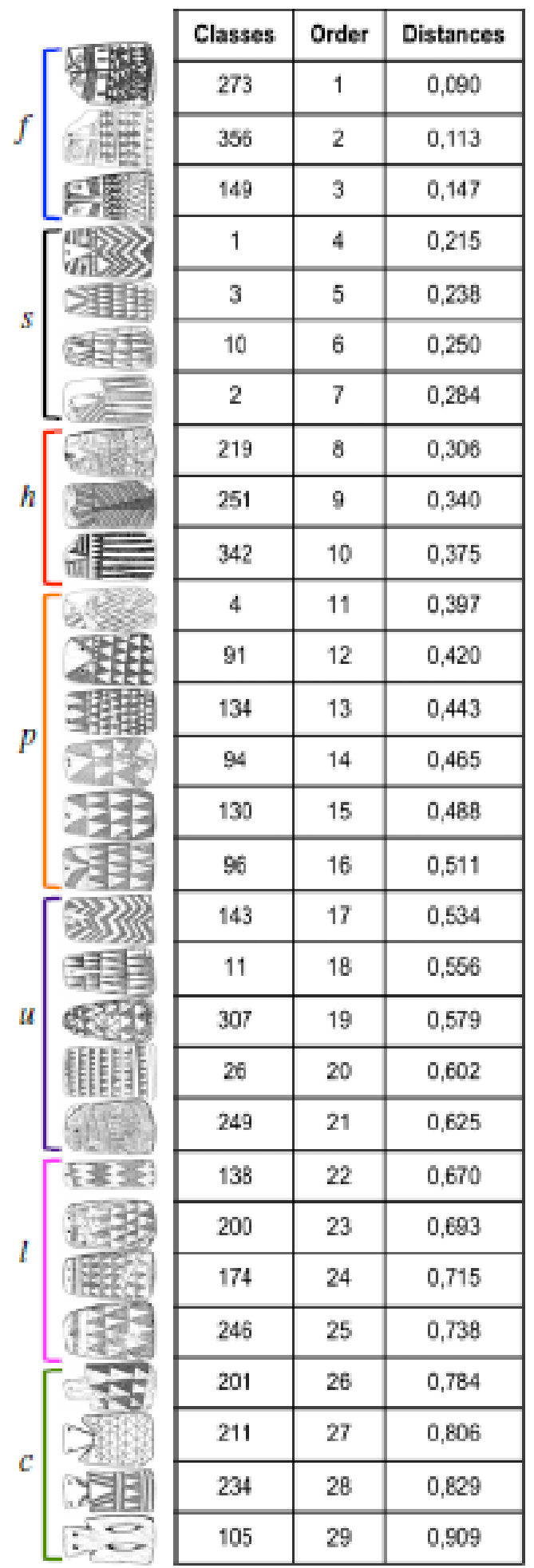

Fig. 15 Comparison between the cladistic types and the occurrence seriation sequence. As we noted before, types $h, c, f, u$, and $l$ are completely supported by cladistic and seriation analysis, whereas $s$ and $p$ are completely supported by seriation 


\section{Discussion}

The strong taxonomical relationships between the different types of plaque can be discussed here according to the results presented above. The strongest relationship, which is supported by the phylogenetic trees and seriation, is established between type $h$, plaques $s$ and $p$. The latter, plaque $p$, usually appears close to types $f$ and $l$ in most of the trees. The second strongest relationship indicated by the trees as well as by seriation is between types $u$ and $l$. Beyond these, there are several relationships that are supported by two of the four trees and by seriation: between types $c$ and $l$, and type $u$ and plaque $p$. Finally, there are other relationships that are only supported by two of the four trees: between types $h$ and $u$, types $f$ and $c$, type $u$ and plaque $s$, and type $l$ and plaque $s$.

The search for ancestry patterns taking into account the polarity of trees depends on the assumed outgroups. In the previous section, we noted that there is some stability in the anthropomorphic $\rightarrow$ abstract hypothesis, from which the outcome model can be summarized as follows (cf., Figs. 12 and 13): type $f /$ type $c \rightarrow p /$ type $l \rightarrow s /$ type $h \rightarrow p /$ type $u$. The seriation outcome (Fig. 15), however, places the two most anthropomorphic types ( $c$ and $f$ ) at both opposite ends, and the other types occupy apparently random positions. Seriation therefore does not support with any great assurance the choice between types $c$ and $f$ as the best outgroup. The two trees obtained from the abstract $\rightarrow$ anthropomorphic polarity model are not alike (Figs. 10 and 11) yet support the following double polarity outline: $s /$ type $h \leftrightarrow$ type $f \leftrightarrow$ type $c /$ type $l /$ type $u$. In general, the seriation outcome agrees better with the tree that considers class no. 3 as its outgroup (Fig. 10).

There are other observations also supported by the majority of the data. For instance, there is a confluence indicating that type $u$ is usually located close to the tips of trees (Figs. 10, 11, and 13), and another convergence suggesting the relatively late position of plaques $s$ and type $h$ (Figs. 11, 12, and 13).

Each of these inferences can be analyzed in conjunction with the available radiocarbon dates and stratigraphic information. Table 6 shows all of the currently available radiocarbon dates for contexts associated with plaques. The archaeological sites are arranged from top to bottom according their age (RCYBP Date). As it can be seen in the "Reference plaque picture" column of this table, many of the plaques belonging to the dated contexts are unfortunately of unknown type. In those cases in which we have access to a picture and/or a full description of the plaque, we have labeled each plaque according to our proposed typology (see "Plaque type" column).

There are several plaques, even with available pictures, for which it is too risky to assign any of our types due to the specific characters considered here. These cases are classed as Indeterminate in the Plaque type column.

Finally, we may highlight and analyze the following nine inferences and points of discussion previously formulated on the basis of the results derived from our dataset, in conjunction with the more general archaeological information (radiocarbon dates and stratigraphy) provided by the overall assemblage of engraved plaques from Southwestern Iberian Peninsula:

1. The relationship between type $h$, plaques $s$, and $p$. The plaques $s$ appear during almost the entire available chronological span, especially between 3173 and 2747 cal BC at Cova das Lapas I (Leiria) and Olival da Pega 2b (Évora) (cf., Table 6). Unfortunately, we do not know the type of the plaque from Gruta 2 da Marmota (Santarém). The plaques $p$ are dated between 3050 and 2897 cal BC at Gruta da Lapa do Fumo (Setúbal) and Anta da Horta (Portalegre). The type $h$ is dated between 2897 and 2792 cal BC at Anta da Horta and Olival da Pega 2b. Most dated contexts with plaques $s$ have also plaques $p$ and type $h$. Moreover, plaques $p$ and type $h$ are found along with plaques $s$ in most of the archaeological sites and 


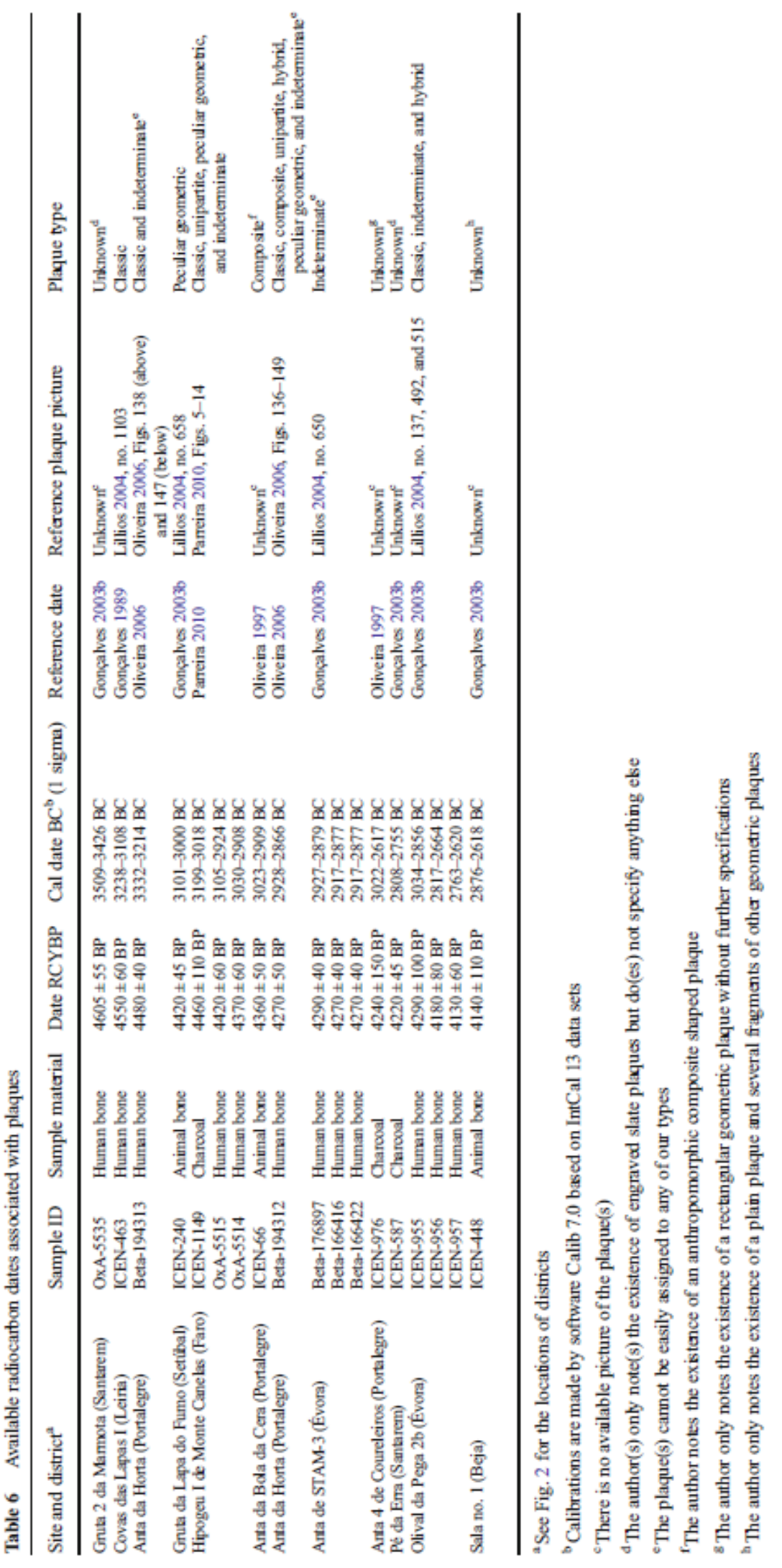


levels of the overall assemblage of plaques. See, for instance, the group recovered from the Reguengos de Monsaraz area (cf., Gonçalves 2003b, Table 2).

2. The relationship between plaques $p$ and type $l$. There are no radiocarbon dates for type $l$. Jazigo de Alcarapinha (Portalegre) is the only site of our study sample in which both type $l$ and plaques $p$ have been found. The other two sites at which type $l$ is documented have not yielded any other types of plaque (Folha das Barradas [Lisboa] and Capela [Portalegre]), and one type $l$ plaque of our sample comes from an unknown site. From a sampling of other sites in the overall assemblage of plaques (Carvão [Évora], Ribera de Odivelas [Beja], Lameira [Portalegre], and Cueva de la Mora [Huelva], among others), the relationship between types $l$ and $p$ is documented in approximately half of the cases.

3. The relationship between types $u$ and $l$. As noted above, Jazigo de Alcarapinha is the only site of our study sample where both type $l$ and, in this case, type $u$ have been found together. However, the relationship between these two types is documented in approximately a quarter of the cases represented by the overall assemblage of engraved plaques.

4. The relationship between plaques $p$ and type $f$. Unfortunately, there is no radiocarbon information for type $f$. At the archaeological sites with type $\mathrm{f}$ and other associated plaques (for instance, Santa Bárbara, and Cueva de la Mora [both in Huelva], Mértola [Beja], Lapa do Bugio [Setúbal], Cabacinhitos [Évora], and Valencina de la Concepción [Seville]), a relationship between type $f$ and plaques $p$ can be observed in half of the cases.

5. The uncertain relationship between the two most explicitly anthropomorphic types of plaques: types $c$ and $f$. We have already noted that there is no radiocarbon information for type $f$. The geographical distributions of these two types throughout the southwest of the Iberian Peninsula are quite different (cf., Lillios 2008-Figs. 2.36 and 2.32), in such a way that both types do not appear together at the same sites. Type $c$ is found in the Portalegre, Castelo Branco, and Cáceres

6. The evolutionary relationships between different types of plaques according to the anthropomorphic $\rightarrow$ abstract polarity model. Recall the summarized proposal (cf., Figs. 12 and 13): type $f /$ type $c \rightarrow p$ /type $l \rightarrow s /$ type $h \rightarrow p /$ type $u$. The lack of radiocarbon dates related to types $f$ and $l$ makes it difficult to test this model, although there are several clear lines of evidence against it. For instance, this model locates type $c$ at the base of the trees, whereas the radiocarbon dates indicate that this type is later than plaques $p$. Indeed, type $c$ is dated from $2966 \mathrm{cal} \mathrm{BC}$ at the site Anta da Bola de Cera (Portalegre), while plaques $p$ are dated from 3050 cal BC at Gruta da Lapa do Fumo (Setúbal). Also, plaques $s$ are earlier than is suggested by the model. However, in agreement with the model, types $u$ and $h$ are relatively late: The oldest date for type $u$ is $3030 \mathrm{cal} \mathrm{BC}$ at Hipogeu I de Monte Canelas (Faro), and for type $h$ is $2897 \mathrm{cal} \mathrm{BC}$ at Anta da Horta (Portalegre). The stratigraphic information currently available provides some evidence that is 
consistent with the hypothetical model, and some that is not. The model is partly fulfilled at Anta da Horta (cf., Oliveira 2006, p. 136ff.): There is a plaque $s$ and one that can be identified as $p$ in the lower level; in the upper level, these two types remain and types $c, \mathrm{u}$, and $h$ emerge. In this case, only the late position of type $c$ is contrary to the model. At Pedra Branca (Setúbal) (cf., Ferreira et al. 1975), the only evidence against the model is the later position of type $l$ in relation to plaques $s$, and types $u$ and $h$.

7. The evolutionary relationship between different types of plaques according to the abstract $\rightarrow$ anthropomorphic polarity model. The summarized proposal for the tree based on class no. 3 (classic) as its outgroup (cf. Fig. 10) is as follows: s/p/type $h \rightarrow$ type $f \rightarrow$ type $l /$ type $u /$ type $c$. This model is in agreement with the following: the early dates for plaques $s$ (3173 cal BC) provided by Cova das Lapas I (Leiria); the later origin and development of plaques $p$ during 3050-2897 cal BC based on the dates from Gruta da Lapa do Fumo (Setúbal) and Anta da Horta (Portalegre); the even later origin of type $u$, from $3030 \mathrm{cal} \mathrm{BC}$ according to the date provided by Monte Canelas (Faro); and finally the most recent origin of type $c$, around 2966 cal BC at Anta da Bola de Cera (Portalegre). However, the early position of type $h$ suggested by the model is at odds with the archaeological data. Type $h$ may not have appeared before $2897 \mathrm{cal} \mathrm{BC}$ according to the radiocarbon dates provided by Anta da Horta. In relation to the available stratigraphic information, the model fits well with Anta da Horta (cf., Oliveira 2006, p. 136ff.), except for the late position of the hybrid plaque. At Pedra Branca (Setúbal) (cf., Ferreira et al. 1975), the only evidence partly against the model is the early appearance and quantity of type $u$ plaques in the lower level, since the model suggests they should appear later. The tree with class no. 26 (unipartite) as its outgroup led to the following proposal (Fig. 11): type $u \rightarrow$ type $l /$ type $c \rightarrow$ type $f \rightarrow s / p /$ type $h$. This model is in contradiction with the late radiocarbon dates for types $u$ and $c$, and with the early dates for plaques $s$. But, it seems to fit with the late location of type $h$. The stratigraphic data from Anta da Horta refutes the model completely, and there is strong evidence against it from Pedra Branca: the late position of type $l$, found only in the upper level; and the presence of all of the plaques $s$ in the lower level when the model suggests they are late.

8. The late position of type $u$. The available radiocarbon dates do not contradict this inference. Type $u$ is dated between $3030 \mathrm{cal} \mathrm{BC}$ at Monte Canelas (Faro) and $2897 \mathrm{cal} \mathrm{BC}$ at Anta da Horta (Portalegre). The stratigraphy of Anta da Horta is consistent with this hypothesis (cf., Oliveira 2006, p. 136ff.), while at Pedra Branca it is not. Here, there are more type $u$ plaques (and of more standardized characteristics) in the lower than in the upper level (Ferreira et al. 1975; Figs. 11, 12 , and 13).

9. The late position of type $h$ and plaques $s$. The available radiocarbon dates do not support this position for plaques $s$, since these are already present from 3173 cal BC at Cova das Lapas (Leiria). In the case of the hybrid type of plaque, this inference seems to be tenable. Type $h$ plaques are dated between 2897 and 2792 cal BC at Anta da Horta and Olival da Pega 2b. The stratigraphy at Anta da Horta supports the expected position of type $h$ but not of plaques $s$. The stratigraphy of Pedra Branca is also contrary to the late appearance of plaques $s$, while type $h$ plaques appear in both levels. 


\section{Conclusions}

The systematic analysis carried out in this study has shed light on several questions which have been intensely debated during the last decades, but it has also allowed us to formulate several new points that had never before been discussed or even considered.

The common ancestor of the entire assemblage of symbolic engraved plaques is a question that cannot yet be completely solved, although a number of relevant pointers are now available. The overall results of our approach show that there are currently two possible outgroups of this entire cultural phenomenon: on one hand, the classic plaques which many researchers have suggested are the oldest, and on the other hand, the figurative head plaques - type $f$. The new proposal of type $f$ as a possible common ancestor is supported by the seriation analysis and, partly, by the cladistic results. We must, however, note that the radiocarbon and the stratigraphic information locate the other more anthropomorphic type [type $c$ ] at a more recent date, thus solving the dilemma cause by the seriation (Fig. 15) and by the trees displayed in Figs. 12 and 13. The idea of type $f$ as the common ancestor would have several consequences for the current study of plaques, for instance, in relation to their area of origin, their diffusion routes, and their cultural antecedents. Unfortunately, there are currently no radiocarbon dates nor stratigraphic information associated with this type of plaque. Different types of plaques have been recovered inside the megalith of Jazigo deAlcarapinha (Elvas, Portalegre), while a single type $f$ plaque was found on the mound (Leisner and Leisner 1959, p. 61). The megalith of Monte da Velha 2 (Serpa, Beja) has two different levels with plaques. A single type $f$ plaque was found in the oldest level, while the remaining plaques found at the site come from the upper level (Soares and Arnaud 1984). Therefore, we must draw attention to the importance that should henceforth be given to the documentation of this type of plaque and to the analysis of its relationships to other types, such as the classic plaques.

At present, and based on the current data, there are firm grounds for considering the classic plaques as the common ancestor of this cultural phenomenon. The cladistic analysis carried out here together with the available radiocarbon and stratigraphic information supports this statement. Most authors maintain that these earliest plaques first appeared in the district of Évora (e.g., Hurtado 1995, 2009; Gonçalves 2006; Lillios 2008, p. 169; Calado 2010). This is the most important megalithic area of the Iberian Peninsula and the place with the greatest quantity not only of classic plaques but also of the overall assemblage. However, the earliest dates available at present come from the western districts close to the Atlantic coast (cf., Table 6 and Fig. 2). This issue will not be discussed here in further detail, since the geographical distribution of plaques has not been systematically analyzed in this paper.

Independently from their region of origin, the classic plaques are indeed those related to the earliest dates (Table 6). On the basis of the parameters used in our analyses, the data taken into consideration, and the evidence of independent outcomes converging into very similar inferences, the cladistic proposal put forward in Fig. 10 must be maintained as the most suitable today. However, an important problem is whether a single stylistic line and direction of change explains the evolution of the entire assemblage of plaques, from the earliest and most abstract (classics) to the more anthropomorphic types. The analyses carried out shed light on new evidence against this assumption.

The strong relationship between three of the most abstract types of plaques (classic, peculiar geometric, and hybrid) has been demonstrated. The seriation outcome locates these three types very close to one another (Fig. 15, letters $s, p$, and $h$ ). Most of the phylogenetic trees indicate this outcome too, and particularly the tree derived from exercise no. 1, which assumes a classic plaque as the common ancestor (cf., Fig. 10, letters 
$s, p$, and $h)$. The available radiocarbon dates and the stratigraphic information also confirm the relationship between these three types of plaques. However, this taxonomical proximity must not necessarily be understood in chronological terms. The classic plaques existed throughout the entire chronological span of the engraved plaque phenomenon. However, type $h$ is known only in the second half of the overall chronological span of plaques, that is, in the third millennium cal BC, but not before. According to the tree of Fig. 10, type $h$ would evolve from plaques $s$, but this would take place between 2897 and 2792 cal BC (cf., Table 6 and Fig. 16). Therefore, there is sufficient evidence to maintain that plaques of abstract symbology were present during the entire chronological duration of this phenomenon: classic plaques from the beginning to the end, and hybrids (with an even more abstract symbology than in the case of classics) only in the second half. At the same time, a series of anthropomorphic types of plaques emerged and evolved. This evidence supports the divergent (tree-like) evolutionary model and is contrary to a progressive and lineal model for the evolution of anthropomorphism in this particular category of material culture.

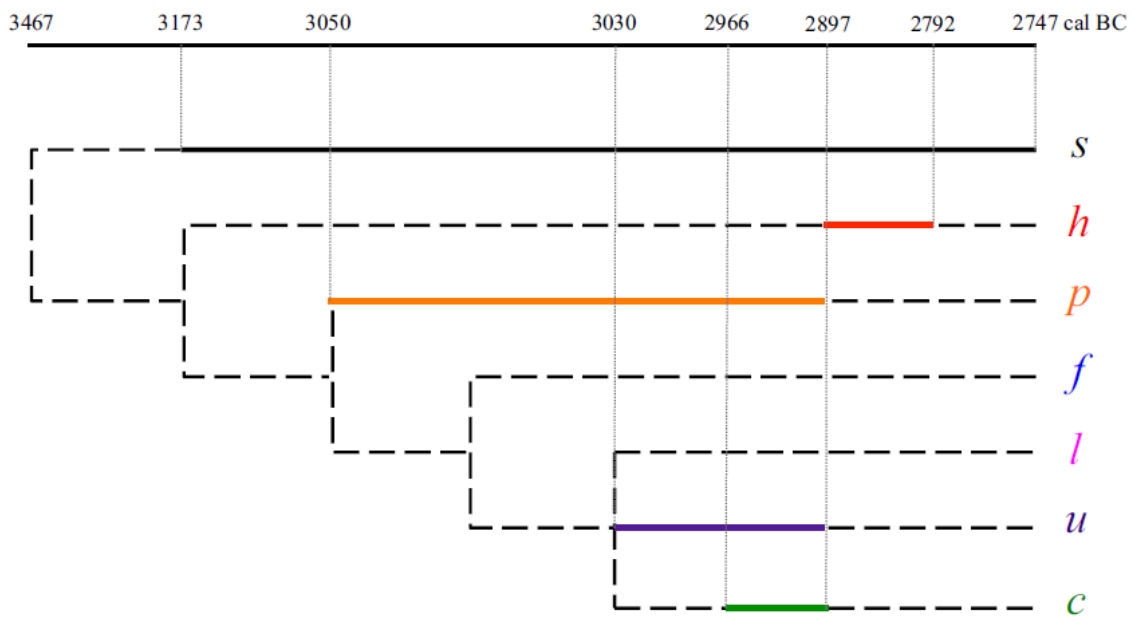

Fig. 16 Synthetic phylogenetic model for the evolution and chronologies of the different types of engraved stones plaque. Along the top, the time axis indicates the calibrated dates to 1 sigma. Along the bottom, the dashed lines show the phylogenetic relationships between the different types of plaque, while the solid lines indicate the chronological ranges of the different types according to the available radiocarbon dates

In this sense, the peculiar geometric plaques appear to have played a relevant role as ancestors of other types of plaques. According to Fig. 10, type f seems to have evolved from plaques $p$ or $s$. But, types $l, u$, and $c$ certainly evolved from plaques $p$ (in Fig. 10, see class nos. 96 and 134 as the possible ancestors of the clade including types $l, u$, and $c$; Fig. 16 summarizes this issue in an easier way). The emergence of these types from plaques p took placed around $3030 \mathrm{cal} \mathrm{BC}$ in the case of type $u$, and $2966 \mathrm{cal}$ BC in the case of type $c$. The late origin and chronological location of types $l$ and $u$ support the point noted above and constitute further evidence against the progressive lineal evolution of the anthropomorphism of plaques. The late chronological location of type $u$ is confirmed by radiocarbon dates (3030-2897 cal BC) (Table 6) and the stratigraphic information does not disprove it. (Unfortunately, there is currently no chronological information related to type $l$.) 
The taxonomical distance between the two most anthropomorphic plaques (types $f$ and $c$ ) is another piece of evidence against a progressive lineal evolution leading toward the anthropomorphism of the engraved plaques. Occurrence seriation places them at the maximum distance possible, at both ends of the model (Fig. 15). The tree of Fig. 10 places them in different clades, separated by plaques $p$. Type $f$ could have evolved from the classic or the peculiar geometric plaques (Figs. 10 and 16), while type $c$ may have evolved from the peculiar geometric plaques. This taxonomical distance is confirmed by the information provided by the archaeological contexts. Type $c$ is almost exclusively found in the northern districts, such as Portalegre, Castelo Branco, Cáceres, Santarém, Leiria, and, rarely, in Évora. In contrast, type $f$ is most common in the districts closest to the Atlantic coast, such as Beja, Leiria, Huelva, Lisboa, Setúbal, and Seville. Unfortunately, there is hardly any stratigraphic information related to type $f$, although this type always appears in the oldest levels in the few known cases noted above. The available stratigraphic information related to type $c$ shows that this type is later than others, as is indicate by the sites of Anta da Bola de Cera (Oliveira 1997) and Anta da Horta (Oliveira 2006, p. 103ff.). Radiocarbon dates support this observation, placing type $c$ not before 2966 cal BC (Table 6).

Based on a well-structured dataset and method, this paper has highlighted the lack of a lineal model but also the existence of a divergent model without a single directionality for the evolution of the anthropomorphic symbology of the Late Neolithic-Chalcolithic I engraved slate plaques of the Southwestern Iberian Peninsula. We believe that the absence of a more progressive pattern of traits and types of plaques as well as the structure and shape of the resulting evolutionary sequence must have a historical explanation, independently of whether we are able to unravel it or not. Future studies could improve the modeling of the evolutionary sequence of the engraved stone plaques set forward here, as well as inquire into its possible underlying reasons and historical factors. But above all, and on the basis of the models suggested here, they will be able to advance toward new historical and methodological questions that are beyond the scope of this paper, for instance, the models and geographical routes by which the plaques spread (see Greenhill and Gray 2005; Buchanan and Hamilton 2009; Lycett 2009; Russell et al. 2014 for a phylogeographic approach), the modes of replication and cultural transmission that underlie the production of this particular category of material culture, the social arena, and the specific roles of plaques within the funerary practices of these communities.

Acknowledgments This study has been conducted within the framework of the research group Tellus. Prehistory and Archaeology in the South of Iberia, HUM-949 - Plan Andaluz de Investigación de la Consejería de Educación y Ciencia de la Junta de Andalucía. I would like to thank the editor, Stephan Shennan, for the consideration given to the initial manuscript and the two anonymous reviewers for their remarks which greatly improved the clarity of the argument.

\section{Compliance with ethical standards}

Conflict of interest The author declares that he has no conflict of interest.

\section{References}

Almagro M (1966) El ídolo de Chillarón y la tipología de los ídolos del Bronce I Hispano. Consejo Superior de Investigaciones Científicas, Madrid

Almagro Gorbea MJ (1973) Los ídolos del Bronce I Hispano. Consejo Superior de Investigaciones Científicas, Madrid 
Archibald JK, MortME, Crawford DJ (2003) Bayesian inference of phylogeny: a non-technical primer. Taxon 52:187-191

Brown JH, Lomolino MV (1998) Biogeography. Sinauer, Sunderland

Buchanan B, Collard M (2007) Investigating the peopling of North America through cladistic analyses of early Paleoindian projectile points. J Anthropol Archaeol 26:366-393

Buchanan B, Collard M (2008) Phenetics, cladistics, and the search for the Alaskan ancestors of the Paleoindians: a reassessment of relationships among the Clovis, Nenana, and Denali archaeological complexes. J Archaeol Sci 35:1683-1694

Buchanan B, Hamilton M (2009) A formal test of the origin of variation in NorthAmerican early Paleoindian projectile points. Am Antiq 74:279-298

Bueno P (1992) Les plaques décorées alentéjaines: approche de leur étude et analyse. Anthropologie 96(2-3):573-604

Calado M (2010) Rock art schist plaques. http://crookscape.blogspot. com.es. Accessed 5 June 2012

Cap H, Delporte P, Joachim J, Reby D (2008) Male vocal behavior and phylogeny in deer. Cladistics 24:917-931

Cardillo M (2010) Análisis cuantitativo de la forma en materiales arqueológicos. Aplicaciones en fenética y cladística. In: Escacena JL, García Rivero D, García Fernández FJ (eds) Clasificación y arqueología: enfoques y métodos taxonómicos a la luz de la evolución darwiniana. Universidad de Sevilla, Sevilla, pp 125-146

Cochrane E (2008) Migration and cultural transmission: investigating human movement as explanation for Fijian ceramic change. In: O'Brien MJ (ed) Cultural transmission and archaeology: issues and case studies. Society for American Archaeology Press, Washington, pp 132-145

Correia V (1917) Os idolos-placas. Arte preistórica. Estudos arqueológicos. Terra Portuguesa 3(13-14):105-119

Darwent J, O'Brien MJ (2006) Using cladistics to construct lineages of projectile points from northeastern Missouri. In: Lipo CP, O’Brien MJ, Collard M, Shennan SJ (eds) Mapping our ancestors: phylogenetic approaches in anthropology and prehistory. Aldine, New York, pp 185-208

Dunnell RC (1971) Systematics in prehistory. Free Press, New York

Ferreira OV (1973) Acerca das placas-ídolos com mãos encontradas em Portugal e o culto da fecundidade. In: Pericot L (ed) Estudios dedicados al Prof. Dr. Luis Pericot. Instituto de Arqueología y Prehistoria, Barcelona, pp 233-240

Ferreira OV, Zbyszewski G, Leitão M, North CT, de Sousa HR (1975) The megalithic tomb of Pedra Branca, Portugal. Preliminary report. P Prehist Soc 41:167-178

Forey PL, Humphries CJ, Kitching IL, Scotland RW, Siebert DJ, Williams DM (2002) Cladistics: a practical course in systematics. Clarendon Press, Oxford

Frankowski E (1920) Estelas discoideas de la Península Ibérica. Museo Nacional de Ciencias Naturales, Madrid

García Rivero D (2010) Introducción a la teoría de la clasificación y a las escuelas taxonómicas (Fenética, Cladística y Taxonomía evolutiva). In: Escacena JL, García Rivero D, García Fernández FJ (eds) Clasificación y arqueología: enfoques y métodos taxonómicos a la luz de la evolución darwiniana. Universidad de Sevilla, Sevilla, pp 61-93

García Rivero D (2013) Arqueología y evolución. A la búsqueda de filogenias culturales. Universidad de Sevilla, Sevilla

García Rivero D, O’Brien MJ (2014) Phylogenetic analysis shows that Neolithic slate plaques from the Southwestern Iberian Peninsula are not genealogical recording systems. PLoS One 9(2):e88296

Goloboff P, Pol D (2005) Parsimony and Bayesian phylogenetics. In: Albert VA (ed) Parsimony, phylogeny, and genomics. Oxford University Press, New York, pp 148-159

Gonçalves VS (1978) Para um programa de estudo do Neolítico em Portugal. Zephyruvs 2829:147-162

Gonçalves VS (1989) Megalitismo e metalurgia no Alto Algarve Oriental. Uma aproximação integrada. Uniarq, Lisboa 
Gonçalves VS (1992) Revendo as antas de Reguengos de Monsaraz. Uniarq, Lisboa

Gonçalves VS (2003a) Pré-História do Occidente peninsular: 4. A ‘síndrome das placas loucas'. Rev Port Arqueologia 6(1):131-157

Gonçalves VS (2003b) STAM-3, a Anta 3 da Herdade de Santa Margarida (Reguengos de Monsaraz). Instituto Português de Arqueologia, Lisboa

Gonçalves VS (2004) As deusas da noite: o projecto "Placa Nostra" e as placas de xisto gravadas da região de Évora. Rev Port Arqueologia 7(2):49-72

Gonçalves VS (2006) Manifestações do sagrado na pré-História do ocidente peninsular 7: as placas híbridas. Rev Port Arqueologia 9(2):27-59

Greenhill SJ, Gray RD (2005) Testing population dispersal hypotheses: Pacific settlement, phylogenetic trees and Austronesian languages. In: Mace R, Holden C, Shennan SJ (eds) The evolution of cultural diversity: a phylogenetic approach. College London University Press, London, pp 31-52

Harmon MJ, Van Pool TL, Leonard RD, Van Pool CS, Salter LA (2006) Reconstructing the flow of information across time and space: a phylogenetic analysis of ceramic traditions from Prehispanic Western and Northern Mexico and the American Southwest. In: Lipo CP, O'Brien MJ, Collard M, Shennan SJ (eds) Mapping our ancestors: phylogenetic approaches in anthropology and prehistory. Aldine Transaction, New Brunswick, pp 209-229

Holden CJ, Meade A, Pagel M (2005) Comparison of maximum parsimony and Bayesian Bantu language trees. In: Mace R, Holden CJ, Shennan SJ (eds) The evolution of cultural diversity: a phylogenetic approach. University College London Press, London, pp 53-65

Hurtado V (1995) Interpretación sobre la dinámica cultural en la Cuenca Media del Guadiana (IV-II Milenio A.N.E.). Extremadura Arqueológica 5:53-80

Hurtado V (2009) Representaciones simbólicas, sitios, contextos e identidades territoriales en el Suroeste peninsular. In: Cacho C, Maicas R, Galán E, Martos JA (eds) Ojos que nunca se cierran: ídolos en las primeras sociedades campesinas. Museo Arqueológico Nacional, Madrid, pp 137-198

Jennings TA, Waters MR (2014) Pre-Clovis lithic technology at the Debra L. Friedkin site, Texas: comparisons to Clovis through site-level behavior, technological trait-list, and cladistic analyses. Am Antiq 79:25-44

Jordan P, Mace T (2006) Tracking culture-historical lineages: can "descent with modification" be linked to "association by descent"? In: Lipo CP, O'BrienMJ, CollardM, Shennan SJ (eds) Mapping our ancestors: phylogenetic approaches in anthropology and prehistory. Aldine, New York, pp 149-167

Jordan P, O'Neill S (2010) Untangling cultural inheritance: language diversity and long-house architecture on the Pacific Northwest Coast. Philos T Roy Soc B 365:3875-3888

Jordan P, Shennan SJ (2003) Cultural transmission, language and basketry traditions amongst the California Indians. J Anthropol Archaeol 22:42-74

Jordan P, Shennan SJ (2009) Diversity in hunter-gatherer technological traditions: mapping trajectories of cultural 'descent with modification' in northeast California. J Anthropol Archaeol 28:342-365

Leisner G, LeisnerV (1959) Diemegalithgräber der Iberischen Halbinsel, der Wester. Walter de Gruyter \& Co, Berlin

Leisner G, Leisner V (1985) Antas do Concelho de Reguengos de Monsaraz. Uniarq, Lisboa

Lillios K (2004) ESPRIT (The engraved stone plaque registry and inquiry tool). http://research2.its.uiowa.edu/iberian/. Accessed 12 August 2015

Lillios K (2008) Heraldry for the dead. Memory, identity, and the engraved stone plaques of Neolithic Iberia. Texas University Press, Austin

Lycett SJ (2007) Why is there a lack of Mode 3 Levallois technologies in East Asia? A phylogenetic test of the Movius-Schick hypothesis. J Anthropol Archaeol 26:541-575

Lycett SJ (2009) Understanding ancient hominin dispersals using artefactual data: a phylogeographic analysis of Acheulean handaxes. Plos One 4:e7404

Lycett SJ, Collard M, McGrew WC (2007) Phylogenetic analyses of behavior support existence of culture among wild chimpanzees. Proc Natl Acad Sci USA 104:17588-17592 
Maddison WP, Donoghue MJ, Maddison DR (1984) Outgroup analysis and parsimony. Syst Zool 33:83-103

Marwick B (2012) A cladistic evaluation of ancient Thai Bronze Buddha images: six tests for a phylogenetic signal in the Griswold Collection. In: Bonatz D, Reinecke A, Tjoa-Bonatz MA (eds) Connecting empires. National University of Singapore Press, Singapore, pp 159176

O'Brien MJ, Buchanan B, Collard M, Boulanger M (2012) Cultural cladistics and the early history of North America. In: Pontarotti P (ed) Evolutionary biology: mechanisms and trends. Springer, New York, pp 23-42

O'Brien MJ, Darwent J, Lyman RL (2001) Cladistics is useful for reconstructing archaeological phylogenies: Palaeoindian points from the southeastern United States. J Archaeol Sci 28:1115-1136

O'Brien MJ, Lyman RL (1999) Seriation, stratigraphy, and index fossils: the backbone of archaeological dating. Kluwer Academic/Plenum, New York

O’Brien MJ, Lyman RL (2000) Applying evolutionary archaeology: a systematic approach. Kluwer Academic/Plenum, New York

O'Brien MJ, Lyman RL (2003) Cladistics and archaeology. University of Utah Press, Salt Lake City

O’Brien MJ, Lyman RL, Collard M, Holden CJ, Gray RD, Shennan SJ (2008) Transmission, phylogenetics, and the evolution of cultural diversity. In: O’Brien MJ (ed) Cultural transmission and archaeology: issues and case studies. Society for American Archaeology, Washington, pp 77-90

O’Brien MJ, Lyman RL, Saab Y, Saab E, Darwent J, Glover DS (2002) Two issues in archaeological phylogenetics: taxon construction and outgroup selection. J Theor Biol 215:133-150

O'Leary MA, Gatesy J (2008) Impact of increased character sampling on the phylogeny of Cetartiodactyla (Mammalia): combined analysis including fossils. Cladistics 24:397-442

Oliveira J (1997) Monumentos megalíticos da bacia hidrográfica do rio Sever. Ibn Maruán, Lisboa

Oliveira J (2006) Património arqueológico da Coudelaria de Alter e as primeiras comunidades agropastoris. Edições Colibrí, Lisboa

Parreira R (2010) O Hipogeu I de Monte Canelas - as placas de xisto gravadas. In: Gonçalves VS, Sousa AC, Gonçalves VS, Sousa AC (eds) Transformação e mudança no Centro e Sul de Portugal: o $4^{\circ}$ e o $3^{\circ}$ milénios a.n.e. Câmara Municipal de Cascais, Cascais, pp 399419

Pol D, Siddall ME (2001) Biases in maximum likelihood and parsimony: a simulation approach to a ten-taxon case. Cladistics 17:266-281

Prentiss AM, Walsh MJ, Foor TA, Barnett KD (2015) Cultural macroevolution among high latitude hunter-gatherers: a phylogenetic study of the Arctic Small Tool tradition. J Archaeol Sci 59:64-79

Riede F (2008) Maglemosian memes: technological ontogeny, craft traditions, and the evolution of Northern European barbed points. In: O'Brien M (ed) Cultural transmission and archaeology: issues and case studies. Society for American Archaeology Press, Washington, pp 178-189

Rodrigues MCM (1986) Estudo ideológico-simbólico das placas de xisto gravadas. Câmara Municipal de Castelo de Vide, Castelo de Vide

Russell T, Silva F, Steele J (2014) Modelling the spread of farming in the Bantu-speaking regions of Africa: an archaeology-based phylogeography. Plos One 9(1):e87854

Sanderson MJ, Donoghue MJ (1989) Patterns of variation in levels of homoplasy. Evolution 43:1781-1795

Shennan SJ (2009) Pattern and process in cultural evolution. University of California Press, Berkeley

Shennan SJ, Collard M (2005) Investigating processes of cultural evolution on the North Coast of New Guinea with multivariate and cladistics analyses. In: Mace R, Holden CJ, Shennan SJ (eds) The evolution of cultural diversity: a phylogenetic approach. University College London Press, London, pp 133-164 
Slowinski JB (1993) 'Ordered' versus 'unordered' characters. Syst Biol 42:155-165

Smith HF, Grine FE (2008) Cladistic analysis of early Homo crania from Swartkrans and Sterkfontein, South Africa. J Hum Evo 54:684-704

Soares AM, Arnaud JM (1984) Escavações do sepulcro megalíticoMV 2 (V. V. Ficalho, Serpa). Archivo de Beja 2(1):67-82

Sober E (2004) The contest between parsimony and likelihood. Syst Biol 53:644-653

Tehrani JJ, Collard M (2002) Investigating cultural evolution through biological phylogenetic analyses of Turkmen textiles. J Anthropol Archaeol 21:443-463

Tehrani JJ, Collard M (2009a) On the relationship between interindividual cultural transmission and population-level cultural diversity: a case study of weaving in Iranian tribal populations. Evo Hum Behav 30:286-300

Tehrani JJ, Collard M (2009b) The evolution of material culture diversity among Iranian tribal populations. In: Shennan SJ (ed) Pattern and process in cultural evolution. University of California Press, Berkeley, pp 99-111

Tehrani JJ, Collard M, Shennan SJ (2010) The cophylogeny of populations and cultures: reconstructing the evolution of Iranian tribal craft traditions using trees and jungles. Philos T Roy Soc B 365:3865-3874

Wiley EO, Siegel-Causey D, Brooks DR, Funk VA (1991) The compleat cladist. A primer of phylogenetic procedures. Museum of Natural History \& Kansas University Press, Lawrence

Wilson EO (1998) Consilience. The unity of knowledge. Vintage Books, New York 